Delft University of Technology

\title{
A Comparison of Hybrid-Electric Aircraft Sizing Methods
}

Finger, D. Felix; de Vries, Reynard; Vos, Roelof; Braun, Carsten; Bil, Cees

DOI

10.2514/6.2020-1006

Publication date

2020

Document Version

Final published version

Published in

AIAA Scitech 2020 Forum

\section{Citation (APA)}

Finger, D. F., de Vries, R., Vos, R., Braun, C., \& Bil, C. (2020). A Comparison of Hybrid-Electric Aircraft Sizing Methods. In AIAA Scitech 2020 Forum: 6-10 January 2020, Orlando, FL [AIAA 2020-1006] (AIAA Scitech 2020 Forum; Vol. 1 PartF). American Institute of Aeronautics and Astronautics Inc. (AIAA). https://doi.org/10.2514/6.2020-1006

\section{Important note}

To cite this publication, please use the final published version (if applicable).

Please check the document version above.

\section{Copyright}

Other than for strictly personal use, it is not permitted to download, forward or distribute the text or part of it, without the consent of the author(s) and/or copyright holder(s), unless the work is under an open content license such as Creative Commons.

Takedown policy

Please contact us and provide details if you believe this document breaches copyrights.

We will remove access to the work immediately and investigate your claim. 


\title{
A Comparison of Hybrid-Electric Aircraft Sizing Methods
}

\author{
D. Felix Finger* \\ Department of Aerospace Engineering, FH Aachen University of Applied Sciences, Aachen, Germany \\ and \\ School of Engineering, RMIT University, Melbourne, Australia \\ Reynard de Vries ${ }^{\dagger}$, Roelof Vos ${ }^{\sharp}$ \\ Faculty of Aerospace Engineering, Delft University of Technology, Delft, The Netherlands \\ Carsten Braun ${ }^{\S}$ \\ Department of Aerospace Engineering, FH Aachen University of Applied Sciences, Aachen, Germany \\ Cees Bil ${ }^{* *}$ \\ School of Engineering, RMIT University, Melbourne, Australia
}

\begin{abstract}
The number of case studies focusing on hybrid-electric aircraft is steadily increasing, since these configurations are thought to lead to lower operating costs and environmental impact than traditional aircraft. However, due to the lack of reference data of actual hybrid-electric aircraft, in most cases, the design tools and results are difficult to validate. In this paper, two independently developed approaches for hybrid-electric conceptual aircraft design are compared. An existing 19-seat commuter aircraft is selected as the conventional baseline, and both design tools are used to size that aircraft. The aircraft is then re-sized under consideration of hybrid-electric propulsion technology. This is performed for parallel, serial, and fully-electric powertrain architectures. Finally, sensitivity studies are conducted to assess the validity of the basic assumptions and approaches regarding the design of hybrid-electric aircraft. Both methods are found to predict the maximum take-off mass (MTOM) of the reference aircraft with less than $4 \%$ error. The MTOM and payload-range energy efficiency of various (hybrid-) electric configurations are predicted with a maximum difference of approximately $2 \%$ and $5 \%$, respectively. The results of this study confirm a correct formulation and implementation of the two design methods, and the data obtained can be used by researchers to benchmark and validate their design tools.
\end{abstract}

\section{Nomenclature}
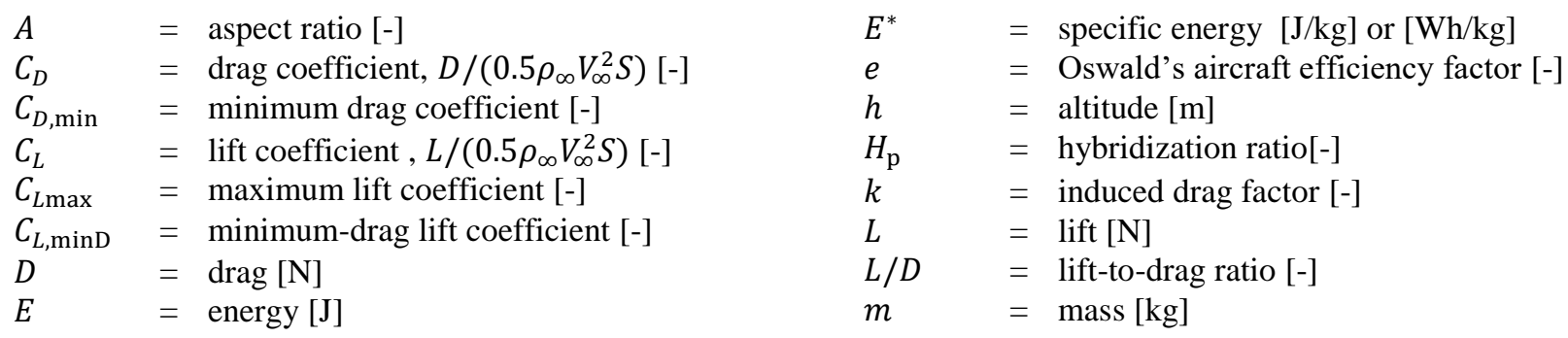

\footnotetext{
* PhD Candidate, FH Aachen UAS / RMIT University, f.finger@fh-aachen.de, AIAA Student Member

${ }^{\dagger}$ PhD Candidate, Delft University of Technology, r.devries@tudelft.nl, AIAA Student Member

* Assistant Professor, Delft University of Technology, r.vos@tudelft.nl, AIAA Associate Fellow

$\S$ Professor, FH Aachen UAS, c.braun@fh-aachen.de, AIAA Member

** Professor, RMIT University, cees.bil@rmit.edu.au, AIAA Associate Fellow
} 


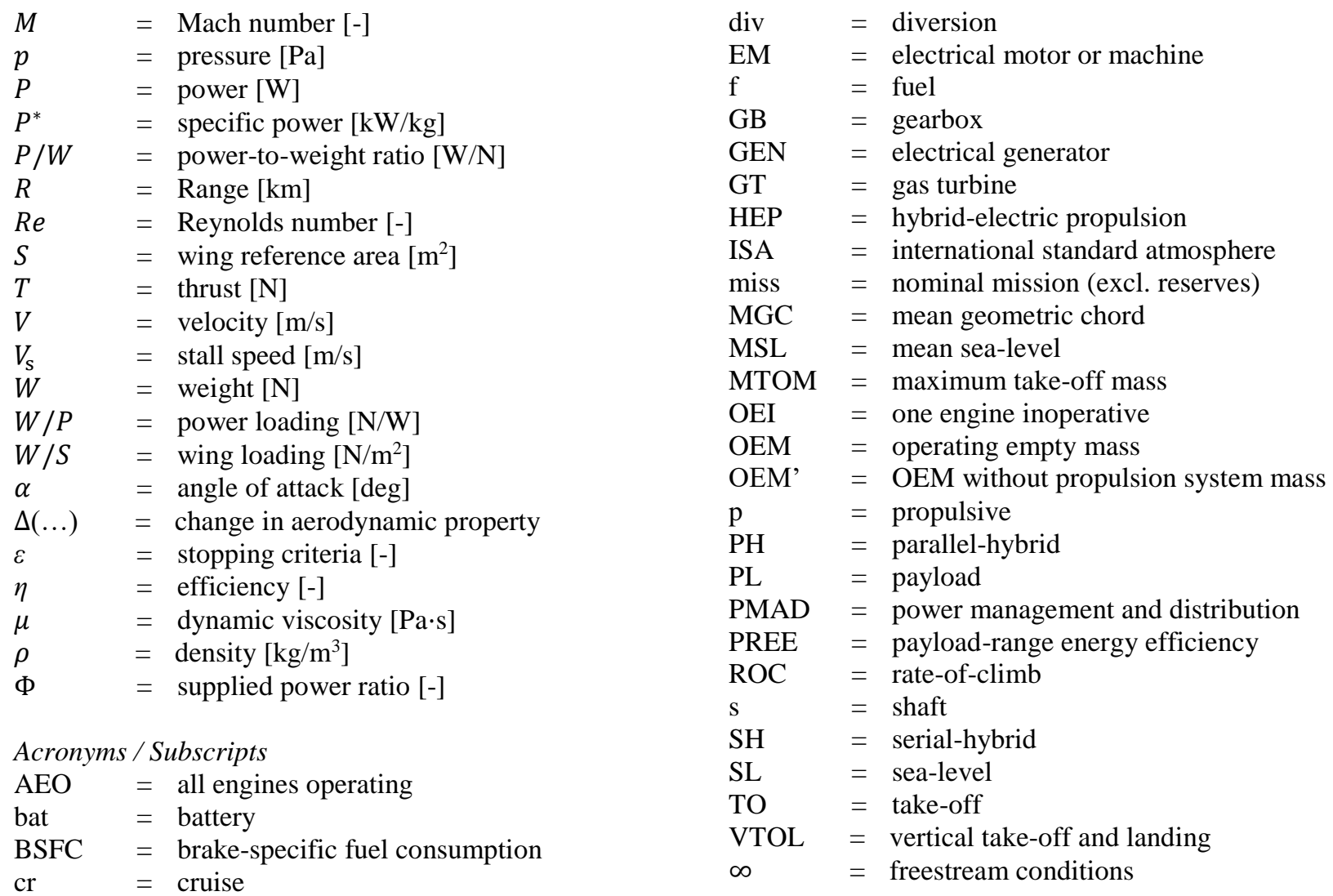

\section{Introduction}

$\mathrm{T}$ HE reduction of greenhouse gases is a relevant topic in every field of today's research. For land-, water-, and airbased traffic, electric propulsion is a potential solution to achieve a reduction in emissions and minimize the use of fossil fuel. Fully electric cars and ships are already in mass production (see e.g. Refs. [1,2]), but only a small number of experimental aircraft currently use electric propulsion technology. This is mainly due to the current battery technology, which limits flight endurance and range [3]. Until battery technology is mature enough [4], hybrid-electric powered aircraft could help further reduce emissions, fuel burn, and noise. Interest in hybrid-electric aircraft design has significantly increased, as shown by the growing number of publications on this topic [5]. However, design procedures and best practices for hybrid-electric aircraft are yet to be developed [6]. In this context, one of the main challenges is the initial sizing of hybrid-electric aircraft, that is, the process of going from the first concept to a baseline design with component masses and engine power that reflect the top-level aircraft requirements.

Many studies are conducted exploring the design space of this new technology. However, these studies often lack transparency regarding the aircraft sizing process. Furthermore, the results of hybrid-electric design studies are usually - if not always - presented without any validation or uncertainty quantification, despite the use of novel design methods. This can, at least partly, be attributed to the fact that validation and verification of design tools for hybridelectric aircraft is a very challenging task due to the lack of available validation data. On the one hand, validation data from existing design studies are scarce because most research does not explicitly list assumptions nor provide sufficient quantitative data to replicate the designs. On the other hand, given that hybrid-electric propulsion is an emerging technology, there are only a very limited number of manned hybrid-electric aircraft that have been flight tested. Examples of hybrid-electric aircraft include a modified motor glider built by the University of Cambridge [7], 
a retrofitted Cessna 337 by Ampaire ${ }^{1}$, and a modified DA40 built by Diamond Aircraft ${ }^{2}$. Since all these aircraft are experimental or prototypes with hybrid-electric propulsion systems fitted to existing conventional aircraft, they are not representative of a fully optimized clean-sheet design, and moreover, only a limited amount of data is publicly available.

At FH Aachen and TU Delft, sizing tools for hybrid-electric aircraft have been independently developed in parallel over the past years. In both approaches, the traditional preliminary sizing methods (Refs. [8-13] were modified to account for hybrid-electric propulsion. The method developed at FH Aachen focuses on the design of general aviation aircraft with special focus on vertical take-off and landing (VTOL). The approach of TU Delft focuses on the design of transport aircraft with special focus on the aero-propulsive effects associated with distributed-propulsion or boundary-layer-ingestion configurations. Both methodologies are designed to provide a first analysis of the available design space for a set of top-level requirements and to determine power-to-weight ratio $\left(P / W_{\mathrm{TO}}\right)$, wing loading $\left(W_{\mathrm{TO}} / S\right)$ and hybridization of power (i.e., the split between electric power and combustion engine power).

In this paper, the two methodologies are compared with the aim of assessing if the general approach to the sizing of hybrid-electric aircraft is valid. The assumptions, discrepancies, and results provided by the two methods are discussed in order to maximize transparency and to provide data to the aircraft design community to benchmark and validate hybrid-electric design tools.
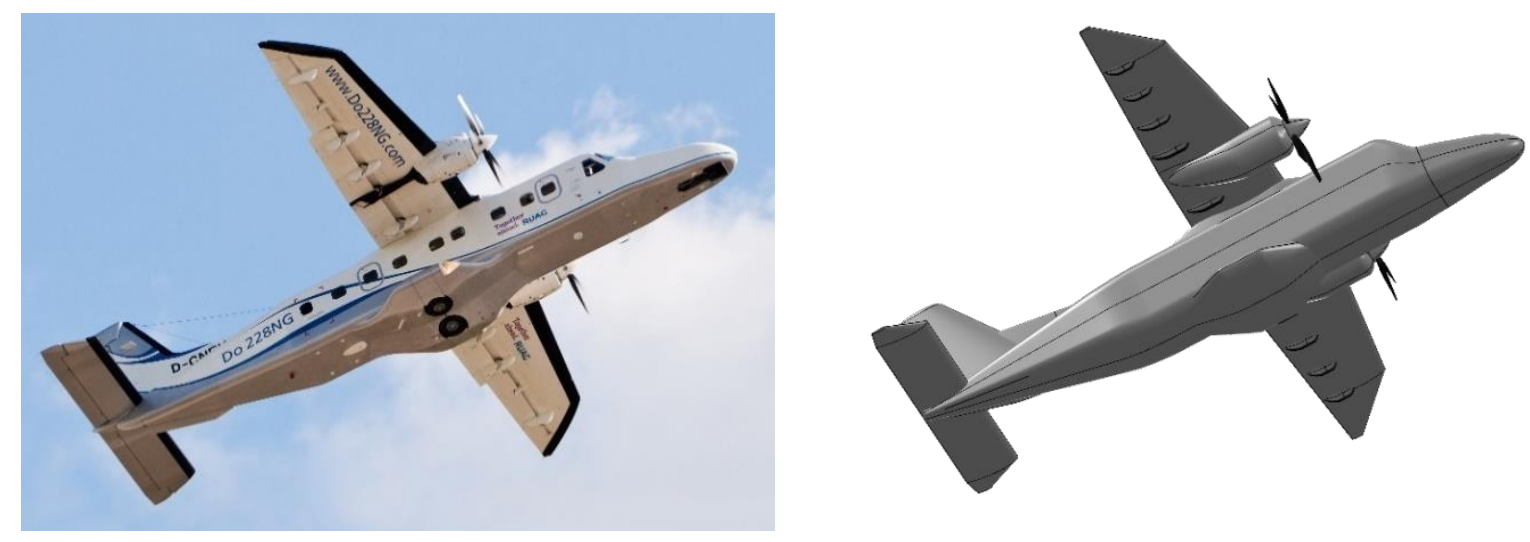

Fig. 1 Comparison between Do 228NG [14] (left) and the 19-seat baseline aircraft (right).

To establish a common baseline, a 19-seat commuter aircraft is used. This reference aircraft is based closely on the Dornier/RUAG Do 228NG, shown in Fig. 1. This aircraft has been analyzed in previous hybrid-electric aircraft studies (see e.g. Refs. [15,16]). Moreover, performance data of the aircraft is available from multiple sources [17-20], and therefore it is well-suited as a reference configuration. First, this baseline aircraft is sized for a common set of toplevel requirements and a conventional turboprop propulsion system. This will show the level of accuracy of the traditional approaches of the sizing methods when comparing the results with data for the Do 228NG. Then, hybridelectric propulsion technology is introduced. Both methods are used to resize the aircraft under consideration of serial, parallel, and fully-electric propulsion system architectures. In this context, resizing is the process of re-matching the aircraft's mass to its desired performance, with only the top-level requirements maintained constant. The results are compared, and differences are highlighted. Finally, in order to verify that the trends of the different approaches match, a sensitivity study is conducted. With this, the gradient of any figure of merit with regard to the analyzed parameters can then be determined, illustrating the impact of each parameter on the final design, and showcasing the differences between both methods. In this way, the study presented in this paper helps to build confidence in the design methods for hybrid-electric aircraft and to understand the impact that hybrid-electric propulsion systems have on the initial sizing process.

\footnotetext{
${ }^{1}$ N. Zazulia, "Hybrid-Electric Cessna 337 Takes Maiden Flight," Avionics International, 6 June 2019. Online. http://www.aviationtoday.com/2019/06/06/ampaire-hybrid-electric-cessna-flight/.

${ }^{2}$ A. M. Lentsch, "Diamond Aircraft 1st Flight Multi-engine Hybrid Electric Aircraft," 7 Nov 2018. Online. http://www.diamondair.at/en/media-center/press-releases/news/article/diamond-aircraft-1st-flight-multi-engine-hybrid-electric-aircraft/.
} 


\section{Approach}

In this section, the design methods of FH Aachen (Sec. II.A.1) and TU Delft (Sec. II.A.2) are briefly described. The main differences between the two methods are then summarized in Sec. II.B. Finally, Sec. II.C describes the simplified powertrain representations and parameterizations used by the two methods.

\section{A. Sizing Methods}

\section{Method A: FH Aachen}

The design methodology formulated at FH Aachen focuses on the design of general aviation aircraft with special focus on vertical take-off and landing (VTOL). The methodology of the sizing process is documented in Ref. [21]. Conventional take-off and landing general aviation aircraft were studied, as shown in Refs. [22-26]. The sizing of VTOL aircraft is discussed in Ref. [27]. The FH Aachen method is developed for aircraft with both parallel-hybrid and serial-hybrid propulsion systems, although it is applicable to conventional propulsors or fully electric propulsion systems as well. Therefore, the algorithm can be integrated into existing design or analysis tools. Its goal is the identification of the optimal design point $\left(P / W_{\mathrm{TO}}\right.$ and $\left.W_{\mathrm{TO}} / S\right)$ of such aircraft and, in addition to this, the corresponding degree of hybridization. Analogous to the classical methods, the methodology is separated into two major parts: point performance, also referred to as the constraint diagram, and mission performance, also known as the mass estimation. For both parts, certain input parameters are necessary, representing the Top-Level Aircraft Performance Requirements (TLARs), which are defined for the individual aircraft. These requirements specify the TLARs, including the flight mission, the aerodynamics, and the propulsion system (number of engines, conventional, serial- or parallel-hybrid, etc.) and its corresponding efficiencies.

An overview of the process is shown in Fig. 2. In the first step, the point performance tool determines the constraint diagram. The required $P / W_{\mathrm{TO}}$, with respect to the $W_{\mathrm{TO}} / S$, is determined for constraints like the desired rate of climb, the desired take-off distance, or the desired cruise airspeed. The mission performance analysis is based on a classical iterative process presented in most aircraft design books (see e.g. Refs. [8,9]). To cover the mix of consumable (fuel) and non-consumable (batteries) energy sources on board, the masses are not treated as fractions, as it is usually done in other sizing algorithms (see e.g. Ref. [10]), but as absolute values. Additionally, the classical endurance and range equations of Breguet are not used to determine mass or energy fractions. Instead, the mission is broken into a large number of short segments and simulated, using a universally valid, energy-based approach. The mission is defined explicitly by the requirements. The fuel mass and battery mass are determined by calculating the required energy for each time step of the flight phase. This energy is split into its consumable and non-consumable parts through the degree of hybridization of the corresponding flight phase and converted into the necessary thrust or power.

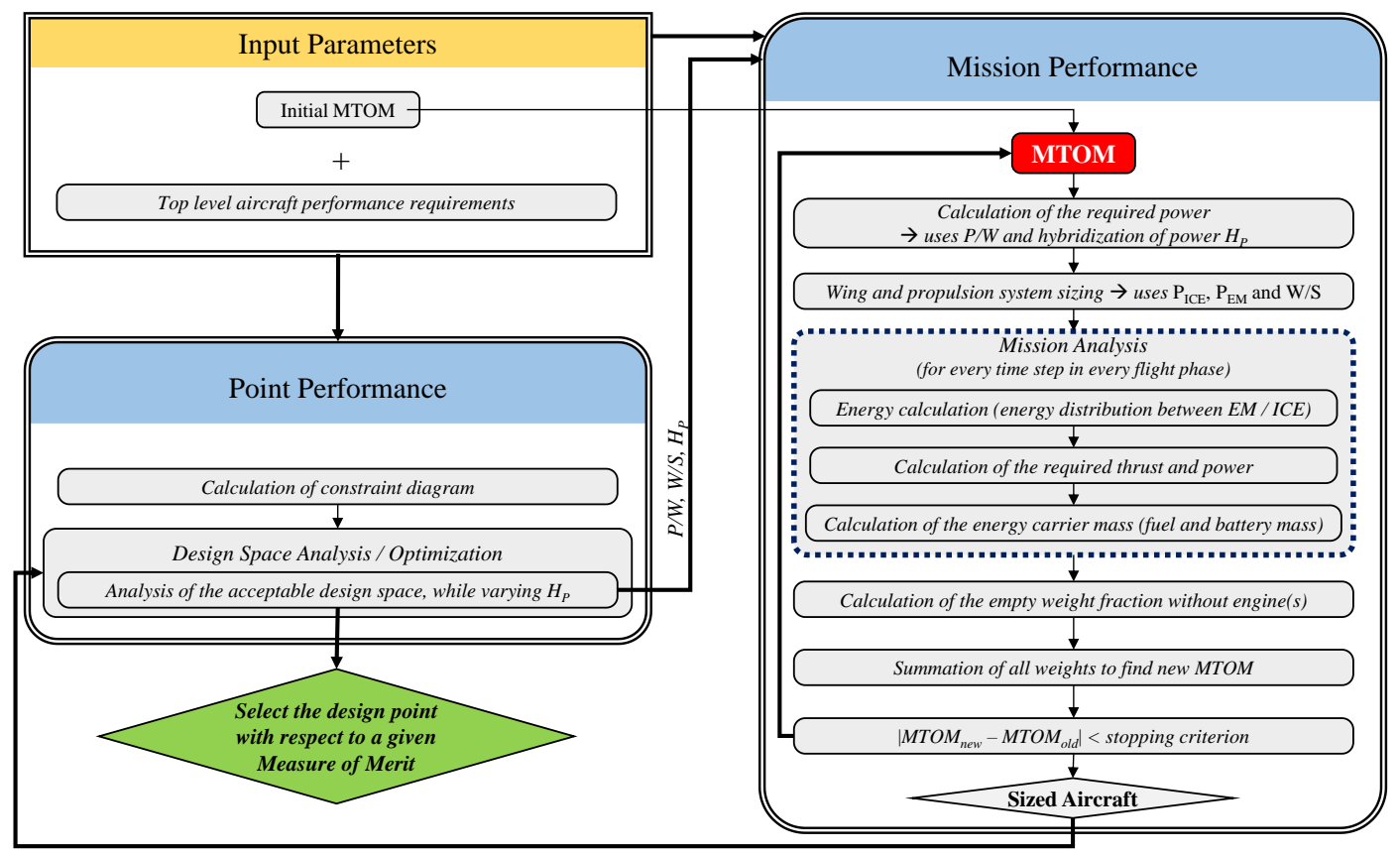

Fig. 2 Flowchart of the sizing process developed by FH Aachen [21]. 
Finally, based on a first estimate for the MTOM, all masses that make up the gross mass are calculated. This can be done by using Class-I or Class-II mass estimation methods. Using the results of the point performance analysis, the propulsion system is sized, as its engine, motor, and integration masses are estimated. In the final step, the empty mass is determined. Because the propulsion system mass is calculated separately, this mass fraction covers the usual operating empty mass without fuel, battery, and engine masses. Based on the new MTOM, the next iteration step can be started. The iteration stops when a certain mass convergence, defined by the stopping criteria $\varepsilon$, is reached.

\section{Method B: TU Delft}

The methodology developed at TU Delft focuses on the preliminary sizing of hybrid-electric transport aircraft, taking into account the aero-propulsive interaction effects present in novel propulsion-system layouts such as distributed propulsion, tip-mounted propulsion, or boundary-layer ingestion systems. The sizing process is documented in Ref. [28], and has been used in several configuration studies [29-31] and sensitivity studies [32,33] of hybrid-electric transport aircraft. Analogously to the approach of FH Aachen, the sizing method combines a point-performance analysis with a mission analysis and subsequent mass estimation, again using power-loading diagrams to represent the design space. However, the two methods differ in several aspects. The main advantages of the method developed by TU Delft are the inclusion of aero-propulsive interaction in the sizing process, and the use of a generic powertrain model which is independent of the type of architecture selected. The main disadvantages, on the other hand, are that the method is not applicable to VTOL and that it requires a more complex representation of the design space due to the use of multiple power-loading diagrams. This difference will be discussed in more detail in Sec. IV. An overview of the sizing method is presented in Fig. 3

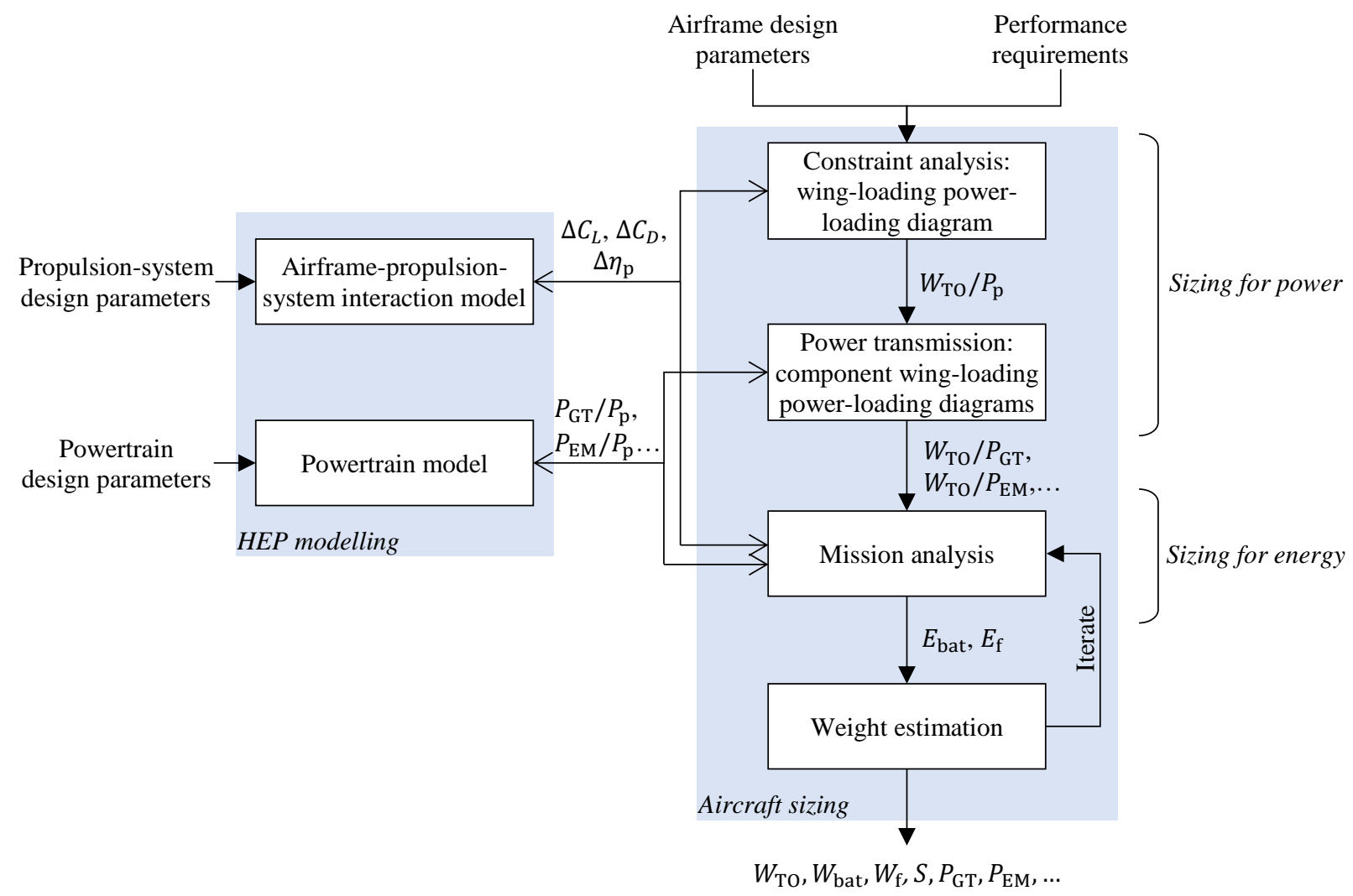

Fig. 3 Flowchart of the sizing processed developed by TU Delft. Adapted from Ref. [34].

First, a constraint analysis is performed in order to determine the wing loading and power loading necessary in order to meet all top-level performance requirements. The point-performance equations used to determine the constraint curves are modified in order to include the changes lift, drag, and propulsive due to aerodynamic interaction between the propulsion system and the airframe. Once the performance constraints have been established in terms of 
the required propulsive power $\left(P_{\mathrm{p}}=T \cdot V\right)$, a powertrain model is used to translate this requirement into a power requirement for each element in the powertrain, thus generating one power-loading diagram per component. This powertrain model is, essentially, a simplified matrix representation of the power balances across each element in the powertrain architecture. It requires up to three power-control variables (throttle, supplied power ratio, and shaft power ratio) to relate the propulsive power to the power required from the energy sources and the different components of the powertrain.

Once the powertrain components haven been sized in terms of power using the power-loading diagrams, a mission analysis is performed to size the aircraft in terms of energy requirements. To this end, a time-stepping approach is performed over a simplified mission profile with an assumed initial MTOM, and the fuel energy and/or battery energy consumption is integrated along the mission. For this, the designer must specify the power-control strategy used during each mission segment. In other words, the throttle setting and power share between the different energy sources or propulsive devices must be specified as input, while the resulting degree-of-hybridization (of energy) is a result of the mission analysis. The resulting fuel and battery masses are included in a modified Class-I mass breakdown of the aircraft, and the MTOM is computed. With this updated MTOM, the mission analysis is re-evaluated until the aircraft mass converges.

\section{B. Differences between Sizing Methods}

Although both methods A and B stem from the well-known Class-I design methods, slightly different results must be expected due to differences in assumptions or modeling approaches. Different models are used for the constraint analysis, the mission analysis, and the systems analysis, with each model having individual strengths and weaknesses. In order to provide an overview, Table 1 highlights the key differences between methods A and B. For a more complete understanding of the rationale behind the two methods, the reader is referred to Refs. [28] and [35].

Both methods use the constraint diagram, also known as the "matching chart", to derive the installed power. However, the main difference between the two methods is the use of a single, combined power-loading diagram in Method A, versus the use of multiple component-oriented power-loading diagrams in Method B. Consequently, Method A assumes a specific power split for all constraints, while Method B is more flexible but requires the designer to select a power split (i.e., a supplied power ratio; see Sec. II.C) for each constraint. The two approaches are described in detail when analyzing these diagrams for a hybrid-electric aircraft in Sec. IV.B. Moreover, a slightly different approach is used to determine the take-off and climb rate constraints. To determine the relationship between power, wing loading, and take-off distance, method A solves an analytic equation from Gudmundsson [10], which takes into account the aircraft's drag and rolling friction. Method B uses a statistical approach based on $\mathrm{C}_{\mathrm{L}, \mathrm{TO}}$, as described by Raymer [8]. To derive the climb rate constraints, the same approach is used to find excess power and thus climb rate; however, climb is performed at different speeds. Method A derives the speed for minimum drag power (maximum $C_{L}^{3 / 2} / C_{D}$ ), while method B assumes a stall margin of $1.2 V_{\mathrm{S}}$, since it is not possible to analytically derive the optimum climb speed when the aero-propulsive interaction effects are considered.

The same difference is reflected in the mission analysis, where Method A accelerates to the speed of minimum drag power, climbs, levels off at the desired altitude, and then accelerates to cruise speed. Method B, on the other hand, climbs at constant $\mathrm{d} M / \mathrm{d} h$, which leads to a smooth climb profile, but is less energy-efficient. A $\mathrm{d} M / \mathrm{d} h$ profile is assumed for descent as well, at an idle throttle setting of $5 \%$, for which the thrust produced is included in the pointperformance equations. Method A handles descent more conservatively: a 10\% throttle setting is considered as idle, but no residual thrust is considered during descent. In this case, the descent speed is adjusted to the velocity for best $L / D$. The taxi, take-off, and landing flight phases are also handled differently. Method A simulates the energy consumption of taxi phases by considering rolling friction, the taxi time and speed, and the take-off energy consumption by applying full power for a determined duration. The landing phase is considered part of the postlanding taxi. Method B covers these flight phases by using Roskam's energy fractions [12], where statistical data is used to describe that part of the mission. In this study, the energy fractions assumed in Method B were selected to match the energy fractions computed in Method A. Furthermore, the fuel reserves required for loiter are computed in a different manner, as shown in Table 1.

Because method A was developed for reciprocating engines, as they are typically found for general aviation, the turboprop's efficiency is described by BSFC values. Method B, on the other hand, describes the gas turbine's thermal efficiency directly, using the factor $\eta_{\text {GT. }}$. In both cases, the turboshaft efficiency is throttle (part-power) corrected, using an empirical formula for jet engines, as described in Ref. [8]. To prevent efficiency from reaching zero at $0 \%$ throttle, the BSFC values of method A have a certain maximum cut-off, whereas the efficiency is considered constant below $15 \%$ throttle by method B. 
Finally, to model the operating empty mass (OEM), both methods use statistical Class I mass estimation methods for this comparison, even though Class II methods from Refs. [8,9,12] and [36] are implemented in Method A. However, Method A defines OEM' as the operating empty mass without a propulsion system. The propulsion system mass is added on top, to account for the large propulsion systems of VTOL aircraft, which are not covered by the typical statistical correlations. Method B considers a conventional OEM definition. For this comparative study, a constant empty-mass fraction is used. For the Do 228 data (OEM/MTOM = 0.609), statistics from Ref. [8] give an OEM/MTOM of approximately 0.6, with a decreasing trend with increasing MTOM. Statistics from Ref. [10] also give an OEM/MTOM of approximately 0.6, with an increasing trend with increasing MTOM. The sensitivity of the OEM fraction to MTOM was found to be small for the commuter class in both cases, and therefore a constant emptymass fraction of $\mathrm{OEM} / \mathrm{MTOM}=0.600$ was selected for Method $\mathrm{B}$, and an equivalent mass fraction of OEM'/MTOM $=0.545$ for Method A, which corresponds to the same value if the propulsion-system mass of the Do 228 is subtracted.

Table 1 Summary of the main differences between the two sizing methods.

\begin{tabular}{|c|c|c|}
\hline Modeling approach & Method A & Method B \\
\hline $\begin{array}{l}\text { Loading diagram: } \\
\text { Design-point selection }\end{array}$ & $\begin{array}{l}\text { Single shaft-power diagram, relative } \\
\text { size of components determined by } \\
\text { power split }\end{array}$ & $\begin{array}{l}\text { One diagram per component; size of each } \\
\text { component determined in respective } \\
\text { diagram }\end{array}$ \\
\hline $\begin{array}{l}\text { Loading diagram: } \\
\text { Powertrain } \\
\text { parametrization }\end{array}$ & $\begin{array}{l}\text { Hybridization of installed power, } H_{\mathrm{p}} \text {, } \\
\text { applied simultaneously to all } \\
\text { constraints in loading diagram }\end{array}$ & $\begin{array}{l}\text { Supplied power ratio, } \Phi \text {, specified for } \\
\text { each constraint in loading diagram }\end{array}$ \\
\hline $\begin{array}{l}\text { Loading diagram: } \\
\text { Take-off constraint }\end{array}$ & $\begin{array}{l}\text { Gudmundsson's method, modified for } \\
\text { offset drag polar (sensitive to drag } \\
\text { and rolling friction) }\end{array}$ & Raymer's take-off-parameter \\
\hline $\begin{array}{l}\text { Loading diagram: } \\
\text { Climb rate constraints }\end{array}$ & $\begin{array}{l}\text { Performed at minimum drag power, } \\
C_{L}^{3 / 2} / C_{D}\end{array}$ & Performed with a stall margin, $V=1.2 V_{\mathrm{s}}$ \\
\hline $\begin{array}{l}\text { Mission analysis: } \\
\text { Taxi }\end{array}$ & $\begin{array}{l}\text { Given taxi time and taxi speed, } \\
\text { rolling friction must be overcome }\end{array}$ & Fuel/energy fractions \\
\hline $\begin{array}{l}\text { Mission analysis: } \\
\text { Take-off / landing }\end{array}$ & $\begin{array}{l}\text { Assume } x \text { minutes at a determined } \\
\text { throttle setting }\end{array}$ & Fuel/energy fractions \\
\hline $\begin{array}{l}\text { Mission analysis: } \\
\text { climb strategy }\end{array}$ & $\begin{array}{l}\text { Climb at } C_{L}^{3 / 2} / C_{D} \text { and then } \\
\text { accelerate to cruise speed }\end{array}$ & $\begin{array}{l}\text { Constant } \mathrm{d} M / \mathrm{d} h ; \text { leads to smooth profile } \\
\text { but slightly higher energy consumption }\end{array}$ \\
\hline $\begin{array}{l}\text { Mission analysis: } \\
\text { descent strategy }\end{array}$ & $\begin{array}{l}10 \% \text { throttle ( idle), which consumes } \\
\text { energy but produces no thrust; } \\
\text { descent at best } L / D \text { speed }\end{array}$ & $\begin{array}{l}5 \% \text { throttle ( idle), which produces some } \\
\text { residual thrust }\end{array}$ \\
\hline $\begin{array}{l}\text { Mission analysis: } \\
\text { Loiter }\end{array}$ & $\begin{array}{l}x \text { minutes at constant altitude and } \\
\text { flight speed, including transients to } \\
\text { reach loiter speed and altitude }\end{array}$ & $\begin{array}{l}x \text { minutes at constant altitude and } \\
\text { optimum flight speed in terms of energy } \\
\text { consumption; transients neglected }\end{array}$ \\
\hline $\begin{array}{l}\text { Turboprop/ Turboshaft } \\
\text { efficiency }\end{array}$ & Constant above a given BSFC value & Constant below a given throttle setting \\
\hline OEM/MTOM fraction & $\begin{array}{l}\text { OEM'/MTOM }=0.545 \\
\text { OEM' excludes powertrain }\end{array}$ & $\begin{array}{l}\text { OEM/MTOM }=0.600 \\
\text { OEM includes powertrain }\end{array}$ \\
\hline
\end{tabular}




\section{Hybrid-electric powertrain definitions}

Multiple different powertrain architectures can be conceived when considering (hybrid-) electric propulsion [37]. Different levels of modeling detail exist, depending on the focus of the design study. In the preliminary sizing methods treated in this paper, a simplified model is used where each component is treated as a "black box" with an associated weight and transmission efficiency. Although a more complete description of these simplified representations can be found in Refs. [38] and [28], a brief overview of the serial and parallel architectures is included here for clarity, to relate the different parameterizations of the two methods to each other.

The parallel hybrid architecture (Fig. 4a) is a configuration in which gas turbine (GT) and electric motor (EM) work in conjunction. Both are mechanically connected to a propeller shaft, often via a gearbox. The total required power is split between GT and EM by a certain degree of hybridization. This allows for a smaller combustion engine, as well as a small electric motor for a given total propulsive power $P_{\mathrm{P}}$. Parallel hybrid architectures are typically a very efficient and light way to add electric power to an aircraft [38].

In a serial-hybrid system (Fig. 4b) the propulsor's shaft is only driven by an EM, while the GT is used to generate electricity for the electric system. The electric system is supplemented by a battery. Sometimes, the unit of GT and generator (GEN) are referred to as a "range extender" (see e.g. Ref. [39]), depending on how the batteries and fuelbased engines are used throughout the mission. Depending on the layout of the system, the GT can run at a constant speed and power setting, which allows it to be optimized for one specific design point. Often, an additional power management system is employed, which can distribute energy between EM and battery, enabling in-flight re-charging of the battery. If the battery is sized accordingly, an aircraft with a serial-hybrid powertrain can also operate in an allelectric mode. This might be desirable from a noise or local emissions perspective.

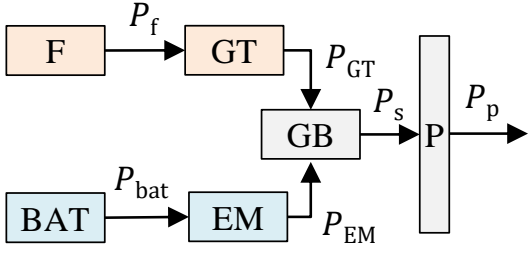

a) Parallel

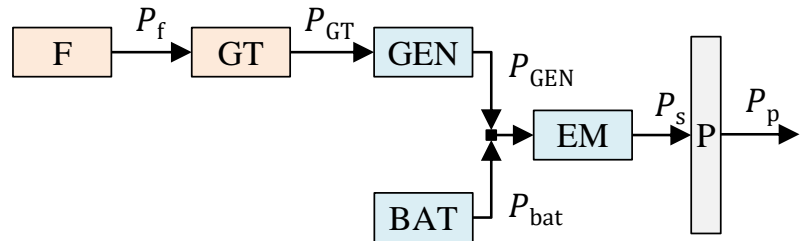

b) Serial

Fig. 4 Simplified representation of the parallel and serial powertrain architectures.

Parallel- and serial-hybrid propulsion systems should not be compared on a one-to-one basis, because this would not be a meaningful comparison. As shown in Refs. [22] and [35], a serial-hybrid system will typically perform worse than a parallel-hybrid system for a similar set of parameters. This is caused by the additional mass that the generator system will add to the aircraft, the corresponding reduction of powertrain efficiency, and the fact that the electric motor must be sized to deliver the total propulsive power. The advantage of serial-hybrid systems is their geometric flexibility. EMs can be installed independently of the location of the GT. This enables distributed propulsion layouts (see e.g. Refs. [32], [40], or [41]), which can take advantage of favorable aero-propulsion interaction. Thereby, the mass increase of the propulsion system is traded against improved aerodynamic efficiency. In this paper, aeropropulsive effects are not considered, to simplify the analysis and improve comparability. Consequently, all serial hybrid designs are expected to be outperformed by the parallel hybrid designs.

The two hybrid-electric propulsion systems shown in Fig. 4 have a mechanical and electrical node, respectively. Therefore, when compared to a conventional fuel-burning powertrain, additional degrees of freedom are available. Method A uses the parameter $H_{\mathrm{P}}$ to describe the hybridization. $H_{\mathrm{P}}$ is the level of hybridization of power, which for parallel architectures is the ratio of the propulsion power of EMs to the total propulsion power at the propeller shaft (see Eq. 1). Note that for serial hybrid-electric powertrains, $H_{\mathrm{P}, \mathrm{PH}}$, as defined in Eq. 1, is always equal to one since only the EM delivers the total installed power. To differentiate between the fully-electric powertrain and to size the generator, in this case, the parameter $H_{\mathrm{P}, \mathrm{SH}}$, is introduced by Eq. 2 .

$$
H_{\mathrm{P}, \mathrm{PH}}=\frac{P_{\mathrm{EM}}}{P_{\mathrm{EM}}+P_{\mathrm{GT}}}
$$




$$
H_{\mathrm{P}, \mathrm{SH}}=\frac{P_{\mathrm{bat}}}{P_{\mathrm{bat}}+P_{\mathrm{GEN}}}
$$

This definition of $H_{\mathrm{P}, \mathrm{SH}}$ is different from the definition provided in Ref. [21]. Previous publications defined $H_{\mathrm{P}, \mathrm{SH}}$ as the ratio between $P_{\mathrm{EM}}$ and $P_{\mathrm{GT}}$. This definition would result in a hybridization ratio of less than 1 for parallel hybrids, and larger than 1 for serial hybrids. For the sake of comparability, the definition is changed for this paper, so that the ratio $H_{\mathrm{P}}$ is less than 1 for both $\mathrm{SH}$ and $\mathrm{PH}$, which makes it similar to the hybridization definition of method $\mathrm{B}$.

Method B, on the other hand, uses the supplied power ratio, which can be expressed as

$$
\Phi=\frac{P_{\text {bat }}}{P_{\text {bat }}+P_{\mathrm{f}}}
$$

Although this parameter governs the power split at the node (i.e., the gearbox for the parallel architecture, or the electrical node for the serial architecture), in this case, the supplied power ratio specifies the value of the split at the energy sources rather than at the node itself, unlike the parameter $H_{\mathrm{p}}$. This formulation is necessary to apply the generalized matrix formulation used to solve the different powertrain architectures, as described in Ref. [28]. Since the definition of the two control variables differs only by the transmission efficiency of the components located between the energy sources and the nodes, they can easily be related to each other through:

$$
\Phi= \begin{cases}\frac{1}{1+\frac{\eta_{\mathrm{EM}}}{\eta_{\mathrm{GT}}} \frac{\left(1-H_{\mathrm{P}, \mathrm{PH}}\right)}{H_{\mathrm{P}, \mathrm{PH}}}}, & \text { for parallel architectures } \\ \frac{1}{1+\frac{1}{\eta_{\mathrm{GT}} \eta_{\mathrm{GEN}}} \frac{\left(1-H_{\mathrm{P}, \mathrm{SH}}\right)}{H_{\mathrm{P}, \mathrm{SH}}}}, & \text { for serial architectures }\end{cases}
$$

\section{Baseline Reference Aircraft}

To build confidence in the abilities of both methods, a conventional baseline reference aircraft is modeled first. For this study, a 19-seat, CS-23 commuter aircraft is selected. Commuter class aircraft (up to $8618 \mathrm{~kg}$ ) are slightly larger than the general aviation category (up to $5760 \mathrm{~kg}$ ), for which Method A is designed, and slightly smaller than the CS25 transport aircraft, for which Method B is typically used. In this way, it is possible to verify that the approaches are generic enough for the sizing of hybrid-electric aircraft in general, and not just limited to the aircraft category for which they were initially intended. In this section, this baseline aircraft is sized for a given set of top-level requirements. This shows the level of accuracy of the traditional approaches of the sizing methods when comparing the results with data for the Do 228NG. These results are subsequently used as a baseline for the hybridization studies of Sec. IV.

\section{A. Definition of Top-Level Aircraft Requirements and Design Assumptions}

The reference aircraft is based closely on the Dornier/RUAG Do 228NG, a twin-turboprop STOL utility aircraft [42]. The Do 228 is built in conventional aluminum construction, features a high wing, and a rectangular-shaped fuselage. The fuselage is not pressurized. The landing gear retracts into a fuselage pod. For propulsion, Honeywell TPE331 engines are used. They are flat-rated to $579 \mathrm{~kW}$ when installed on the Do 228 [17], but are designed to produce up to $701 \mathrm{~kW}$ [19]. The reference aircraft is sized for a typical commuter mission, including diversion, 30 minutes of loiter, and additional contingency fuel reserves, as specified by the regulations [43]. The mission specification and top-level design requirements are shown in Table 2.

The selected aircraft performance requirements are based on information given in Refs. [17] and [20], while the propulsion system data is obtained from manufacturer data and the Do 228's pilot's operating handbook [18]. The following deviation was made from the published data. The published take-off distance is given as $793 \mathrm{~m}$, including the climb to obstacle height. Using the pilot's operating handbook, take-off ground roll is determined as $650 \mathrm{~m}$. Moreover, the mission requirements are extracted from the payload-range diagram of the aircraft, presented in Fig. 5. 
Table 2 Mission and performance requirements.

\begin{tabular}{lclc}
\hline \hline Parameter & Value & Parameter & Value \\
\hline Take-off distance $[\mathrm{m}]$ & 793 & Diversion speed $V_{\mathrm{div}}[\mathrm{m} / \mathrm{s}]$ & 85 \\
Taxi/Take-off altitude $h_{\mathrm{TO}}[\mathrm{m}]$ & 0 & AEO ROC at SL $[\mathrm{m} / \mathrm{s}]$ & 8 \\
Cruise altitude $h_{\mathrm{cr}}[\mathrm{m}]$ & 3000 & OEI ROC at SL $[\mathrm{m} / \mathrm{s}]$ & 2 \\
Landing/Taxi altitude $h_{\mathrm{L}}[\mathrm{m}]$ & 0 & Range (baseline) $R[\mathrm{~km}]$ & 396 \\
Diversion altitude $h_{\mathrm{div}}[\mathrm{m}]$ & 1000 & Diversion range $R_{\mathrm{div}}[\mathrm{km}]$ & 270 \\
Loiter altitude $h_{\mathrm{loiter}}[\mathrm{m}]$ & 450 & Loiter time [min] & 30 \\
Cruise speed $V_{\mathrm{cr}}[\mathrm{m} / \mathrm{s}]$ & 115 & Contingency fuel $[\%]$ & 5 \\
Stall speed $V_{\mathrm{s}}[\mathrm{m} / \mathrm{s}]$ & 34.5 & Payload (baseline) $m_{\mathrm{PL}}[\mathrm{kg}]$ & 1960 \\
\hline
\end{tabular}

The values of the design parameters and additional input assumptions selected to meet these top-level requirements are included in the Appendix for traceability. The aerodynamic modeling is discussed in Sec. III.B. The designs were found to be especially sensitive to the aerodynamic modeling of the aircraft and to the performance characteristics of the turboshaft engine. For the power lapse and specific fuel consumption (or thermal efficiency) of the engine, a surrogate model is built based on TPE331 performance data [19]. Due to the flat-rating of the TPE331 used on the Do228, the engine was found to be able to produce maximum power at all combinations of flight speed and altitude considered in this study. The specific fuel consumption of the engine, meanwhile, is computed as a function of flight speed and altitude using the surrogate model, and additionally corrected for part-throttle, as mentioned in Sec. II.B.

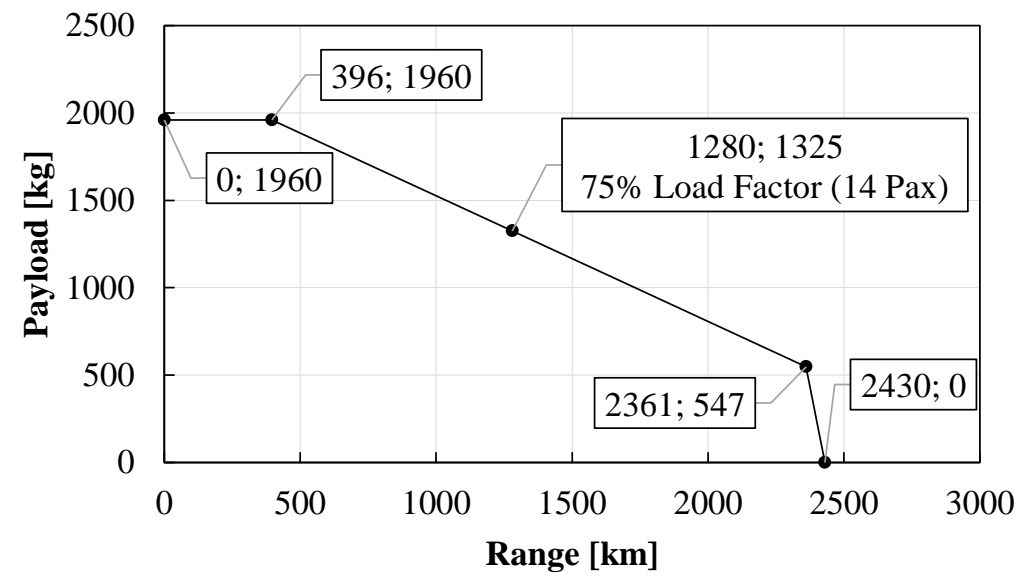

Fig. 5 Payload-range diagram of the Do 228NG. Data taken from Ref. [17].

\section{B. Aerodynamic Modelling}

Because no aerodynamic data for the Do $228 \mathrm{NG}$ is available in the public domain, the aerodynamic performance had to be estimated by the authors. To increase fidelity, the authors decided against a classical drag buildup to determine the drag polar. The Do 228 features under-the-wing engines, which contribute considerably to interference drag and also reduce the wing efficiency [44]. Additionally, it has a box-shaped fuselage with multiple kinks and significant upsweep (see Fig. 1), which complicates drag estimation. Götten et al. [45] highlight that drag build-up models can give significantly wrong results when applied to non-standard aircraft configurations. Therefore, Reynolds Averaged Navier Stokes (RANS) CFD simulations were carried out to determine the drag polar of the concept. The reference geometry was created in OpenVSP using 3-view drawings of the Do 228NG.

The simulation was set up according to the recommendations outlined in Ref. [46]. The OpenVSP geometry was transferred to Siemens' simulation package StarCCM+ via the .STL standard. Then, the flow field about the models was simulated using a steady-state RANS approach, using the SST k- $\omega$ (Menter) turbulence model. Further details on this methodology can be found in Ref. [47]. The RANS equations were solved using the assumptions of incompressible 
flow with a Semi Implicit Method for Pressure Linked Equations (SIMPLE) approach. The bullet-shaped flow field was divided into finite volumes using StarCCM+'s unstructured Cartesian cut cell mesher with a dedicated prism mesh, which discretizes the boundary layer. Boundary layer thickness was determined using the Schlichting's methods [48], ensuring $\mathrm{y}^{+}$values below 1 on the aircraft's surfaces. The surface mesh size was adjusted to give approximately 70 cells over the wing in chordwise direction. Lift and drag forces on the models' bodies were obtained by integrating the cells' shear stress tensor and their pressures. To decrease the computational effort, a half-model was used, and a symmetry condition was applied. Grid-independent results were then obtained for a mesh size of 18.4 million cells. StarCCM+'s mesh optimization scheme was employed, which improves cell skewness angles, cell aspect ratio, and volume change between cells. Further information on the simulation parameters is presented in Table 3. A sample pressure coefficient distribution is shown in Fig. 6.

Table 3 Operating conditions selected for the CFD simulations of the reference aircraft geometry.

\begin{tabular}{lc}
\hline \hline Parameter & Value \\
\hline Free stream velocity $V_{\infty}[\mathrm{m} / \mathrm{s}]$ & 55 \\
Reference pressure $p_{\infty}[\mathrm{Pa}]$ & 101,325 \\
Density $\rho_{\infty}\left[\mathrm{kg} / \mathrm{m}^{3}\right]$ & 1.225 \\
Dynamic viscosity $\mu[\mathrm{Pa} \cdot \mathrm{s}]$ & $1.812 \cdot 10^{-5}$ \\
Reynold's number $R e_{\text {MGC }}[-]$ & $6.967 \cdot 10^{6}$ \\
Mach number $M_{\infty}[-]$ & 0.161 \\
Turbulence intensity (inlet) [-] & $1 \%$ \\
Turbulent viscosity ratio (inlet) [-] & 10 \\
\hline \hline
\end{tabular}

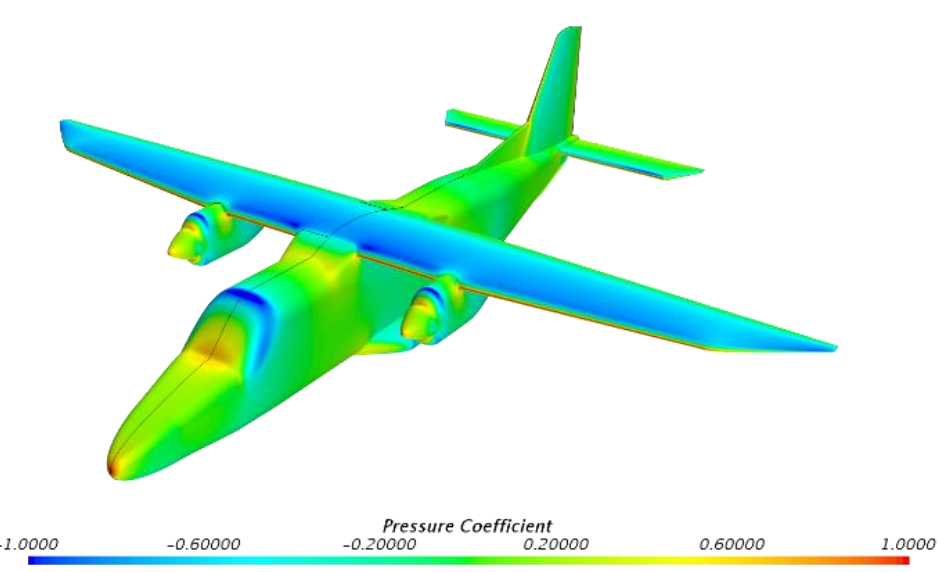

Fig. 6 Pressure coefficient distribution on the aircraft model at $\alpha=0^{\circ}$. Propeller effects not included.

Nine operating points were calculated using this approach: from $-4^{\circ}$ to $10^{\circ}$ angle of attack, in steps of $2^{\circ}$. Then a curve fit was applied to find the lift coefficient at minimum $\operatorname{drag} C_{L, \min D}$, the minimum drag coefficient $C_{D \min }$, and Oswald's aircraft efficiency factor $e$. These parameters allow the construction of an asymmetric parabolic drag polar given by:

$$
\begin{gathered}
C_{D}=C_{D, \min }+k \cdot\left(C_{L}-C_{L, \min D}\right)^{2} \\
k=\frac{1}{\pi \cdot A \cdot e}
\end{gathered}
$$

Additionally, a penalty was applied to the drag values obtained from RANS CFD since the drag from leakage and protuberance, cooling, propeller interaction, and other miscellaneous drag sources are not accounted for. A $20 \%$ increase of the total zero-lift drag is appropriate to account for the under-prediction of these effects by CFD [49]. The curve fit parameters are shown in Table 4. The simulation results are presented in Fig. 7. A maximum $L / D$ of 16 is obtained at a $C_{L}$ of 0.75 . 
Table 4 Drag polar characteristics.

\begin{tabular}{lc}
\hline \hline Parameter & Value \\
\hline Aspect ratio $A[-]$ & 9.00 \\
Minimum drag coefficient $C_{D, \min }[-]$ & 0.029 \\
Minimum-drag lift coefficient $C_{L, \min D}[-]$ & 0.17 \\
Oswald's aircraft efficiency factor $e[-]$ & 0.63 \\
\hline \hline
\end{tabular}

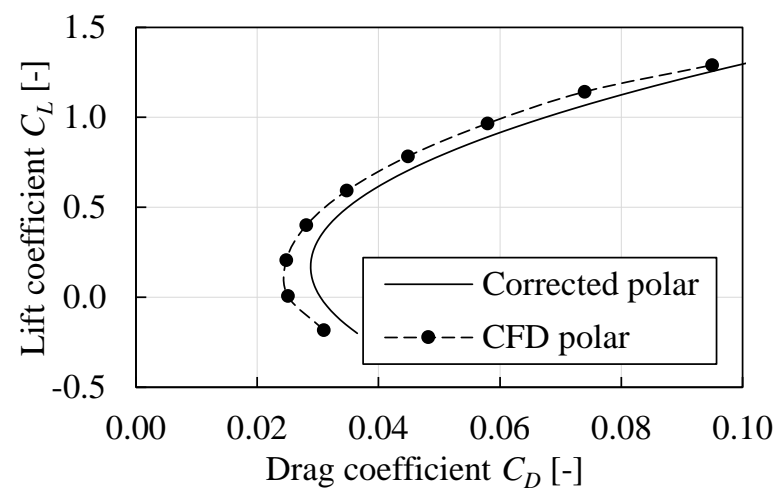

a) Drag polar

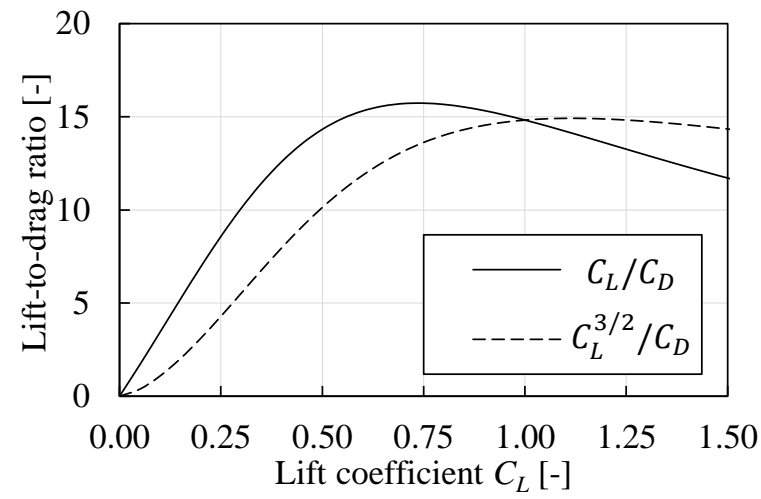

b) Lift-to-drag ratio

Fig. 7 Drag polar characteristics obtained from the CFD simulations of the reference aircraft geometry.

\section{Sizing of the Reference Aircraft}

The first step of the sizing process is to determine the wing loading and power-loading or power-to-weight ratio of the aircraft. To this end, the results obtained from both methods for the Do 228 is shown in Fig. 8. The constraint lines are constructed with the requirements from Sec. III.A and the aerodynamic data from Sec. III.B. For completeness, all additional performance requirements specified by the regulations (Refs. [50,51]) have been included in grey lines in Fig. 8. However, these additional constraints were found to not actively constrain the design space, and are therefore not discussed in further detail.

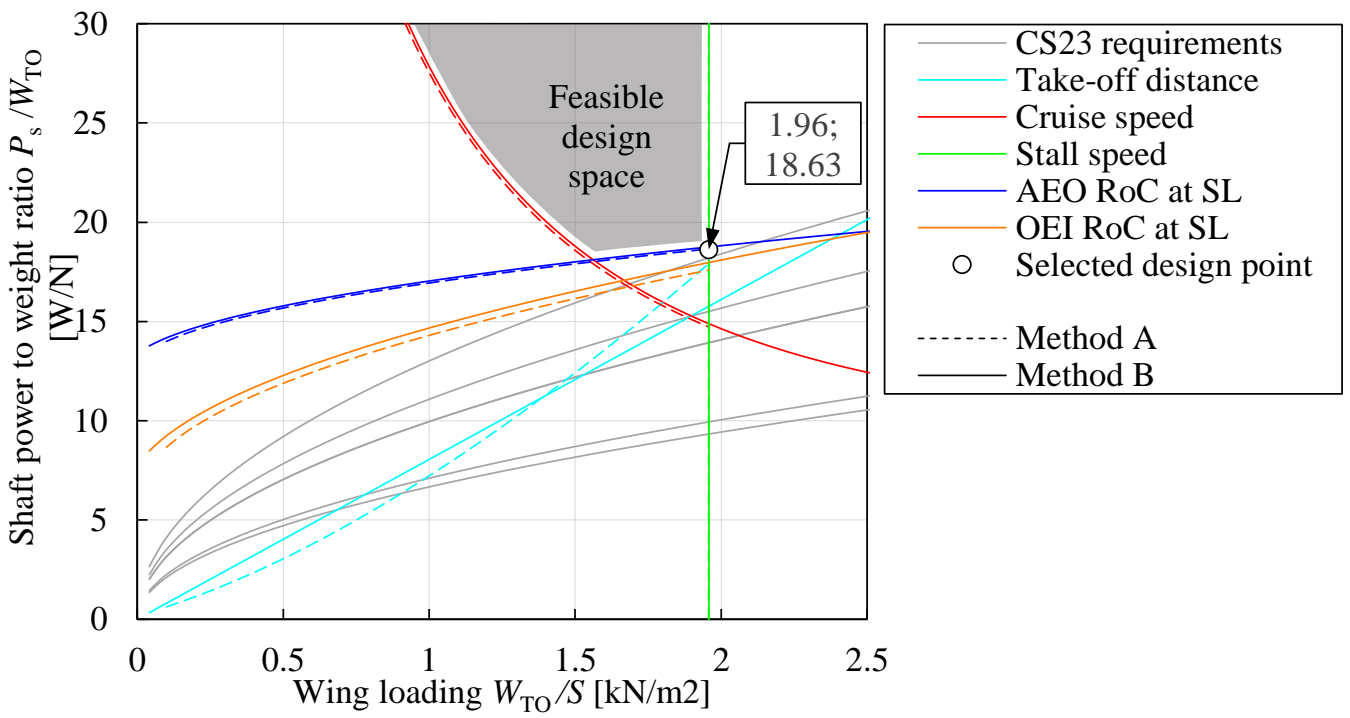

Fig. 8 Performance constraint diagram of the reference aircraft configuration, corrected to maximum throttle. 
The agreement of both methods is good, although slight variations can be observed in the diagram. The most glaring disparity is the take-off distance constraint. Method A uses Gudmundsson's approach, which correlates $W_{\mathrm{TO}} / S$ and $P S W_{\mathrm{TO}}$ in a nonlinear fashion. Method B uses Raymer's linear regression approach, which gives more optimistic values at high wing loading. The one-engine inoperative (OEI) rate-of-climb (ROC) constraint at sea level (SL) is found to differ slightly due to the different flight speed assumed in either method (see Table 1), with method B being slightly more conservative. The all-engines operating (AEO) ROC constraint and the stall speed constraint, which determine the design point, are found to show a good agreement between the two methods, as well as the cruise speed constraint. Consequently, the design points obtained from both methods are practically identical, and differ less than $1 \%$ from the design point of the Do 228 for the selected design parameters, as shown in Table 5.

Table 5 Design point comparison.

\begin{tabular}{lccccc}
\hline \hline Design Point & Do 228 & \multicolumn{2}{c}{ Method A } & \multicolumn{2}{c}{ Method B } \\
\hline & Reference data & Value & Difference & Value & Difference \\
\hline$W_{\mathrm{TO}} / S\left[\mathrm{~N} / \mathrm{m}^{2}\right]$ & 1962 & 1957 & $-0.3 \%$ & 1958 & $-0.2 \%$ \\
$P_{\mathrm{S}} / W_{\mathrm{TO}}[\mathrm{W} / \mathrm{N}]$ & 18.44 & 18.65 & $+1.1 \%$ & 18.63 & $+1.0 \%$ \\
\hline \hline
\end{tabular}

Using the $P / W_{\text {Tо }}$ and $W_{T O} / S$ data from the constraint diagrams, the mission performance analysis is then carried out, and the energy requirements to match the desired mission. This is conducted for three different points of the Do 228's payload-range diagram: a short-range mission with maximum payload, a medium-range mission with $75 \%$ load factor, and a long-range mission that corresponds to maximum fuel and minimum payload (see Fig. 5). As the Do 228 flies all missions with the same MTOM, the sizing methods should also return the same gross mass for each of the points.

The sizing results of all points of the payload-range diagram are shown in Table 6 for both methods. The difference in MTOM between the reference aircraft and the sizing results of the numerical methods is less than $4 \%$. This is a remarkable result, especially when considering that these methods are intended for conceptual design work, and the fidelity of the modeling is relatively low. As a general trend, Method A seems to be slightly too conservative when estimating MTOM (+0.5 to $+3.8 \%)$, but no clear trend regarding the influence of the design range can be seen. Method B gets an excellent result $(+0.3 \%)$ for the short mission, but slightly under-predicts MTOM for longer ranges (up to 3.3\%). Furthermore, to verify that the MTOM estimation of the aircraft is correct and not an artifact of counteracting effects in the component mass estimation, the component masses of both methods for each mission are compared to reference data in Fig. 9. This figure shows that, apart from the fuel mass, both methods are capable of sizing the different components with reasonable accuracy.

Table 6 MTOM computed for the conventional aircraft configuration and comparison to reference aircraft data.

\begin{tabular}{ccccccc}
\hline \hline \multicolumn{2}{c}{ Mission } & Reference & \multicolumn{2}{c}{ Method A } & \multicolumn{2}{c}{ Method B } \\
Range [km] & Payload [t] & MTOM [t] & MTOM [t] & Diff. [\%] & MTOM [t] & Diff. [\%] \\
\hline 396 & 1.96 & 6.40 & 6.64 & $+3.8 \%$ & 6.42 & $+0.3 \%$ \\
1280 & 1.33 & 6.40 & 6.43 & $+0.5 \%$ & 6.40 & $0.0 \%$ \\
2361 & 0.55 & 6.40 & 6.49 & $+1.4 \%$ & 6.19 & $-3.3 \%$ \\
\hline \hline
\end{tabular}

Figure 9 shows that the largest discrepancy between the reference and the results of both methods is found for the fuel mass. Fuel mass is directly connected to the overall efficiency of the aircraft, and almost all modeling errors manifest themselves in an increase in fuel burn. The sensitivity of fuel burn to the aerodynamic characteristics of the aircraft and to the performance map of the turboshaft engine make the discrepancy hard to trace back to a specific assumption or modeling error. The largest relative difference is found for the short-range mission, which also has the lowest absolute fuel mass. Consequently, the relative deviation from the reference data is the largest, even though the fuel mass is only over-predicted by approximately $60 \mathrm{~kg}$ (see Table A.3). The larger error for shorter missions also suggests that different reserve-fuel requirements might play a role. For example, the diversion range of the reference aircraft might be lower than assumed here. 


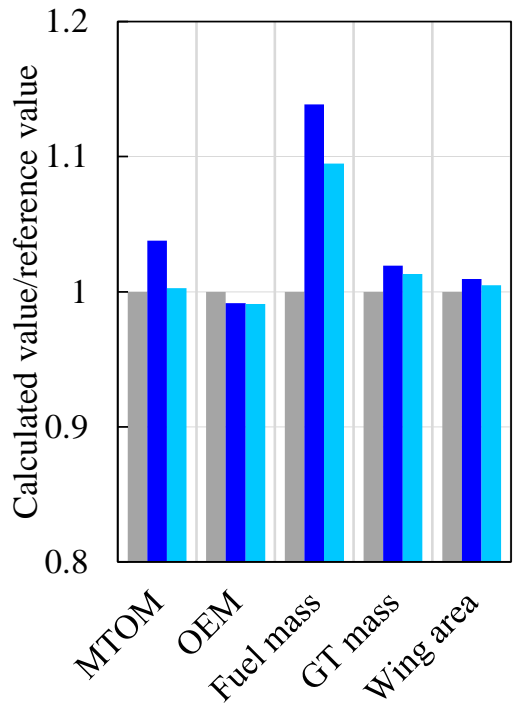

a) Short range mission

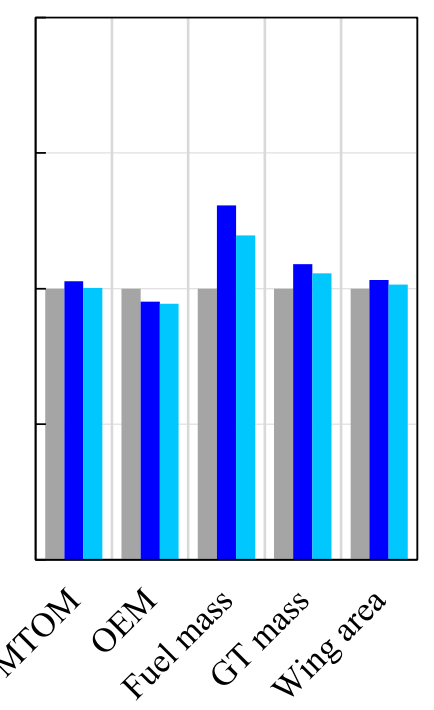

b) Medium range mission

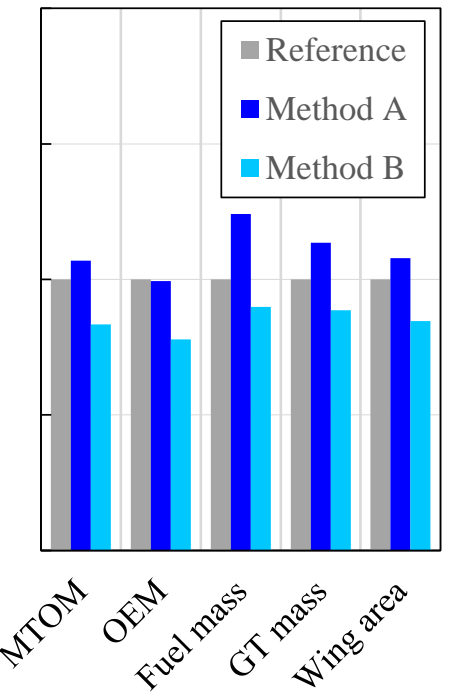

c) Long range mission

Fig. 9 Comparison between results obtained from the two sizing methods and reference aircraft data.

The inherent differences of the mission analyses of both methods play a factor as well: the taxi, take-off, and landing fuel fractions are calculated differently, a different climb and descent strategy is used, and the variable turboshaft efficiency is implemented differently, as discussed in Sec. II.B. Especially the last two points have an important effect for the shorter missions, as a larger fraction of the mission is spent in off-design conditions, instead of in cruise flight. To further investigate possible differences in the mission analysis, Fig. 10 shows the mission profile obtained by the two sizing methods for the short-range mission. Note that, for such a short mission, the reserves play an important role in determining the total fuel weight. Although no mission data is available for the reference aircraft, Fig. 10 shows that the two methods produce similar mission profiles. The climb and descent profiles of Method B are smoother but lead to slightly higher energy consumption, as discussed in Sec. II.B. Moreover, Method A explicitly models the taxi-out, take-off, landing, and taxi-in phases, while Method B does not. For Method B, the nominal mission starts at take-off speed and ends at the approach speed. Finally, Method A always accelerates/decelerates and climbs/descends between mission phases, while Method B presents a discontinuity at the beginning and end of the loiter phase, for which no transition phases are modeled. However, despite these differences, the block fuel consumption computed by the two methods does not differ significantly, as reflected in Fig. 9.

\section{Hybrid-Electric Aircraft}

In this section, the conventional, parallel-hybrid, serial-hybrid, and fully electric aircraft are compared against each other. The comparison is conducted in detail for the three missions that were analyzed in Sec. III, and then, in more general terms, for three parameter sweeps.

\section{A. Assumptions}

The differences observed with the conventional baseline aircraft in Sec. III can largely be attributed to different modeling approaches for the mission reserves and powertrain components. To exclude these differences - which are not inherent to the formulation of the two sizing methods - several additional simplifications are made for the comparison of hybrid-electric aircraft. In this way, the additional discrepancies due to the incorporation of hybridelectric propulsion can be isolated. In the following paragraphs, the simplifications are briefly explained. 


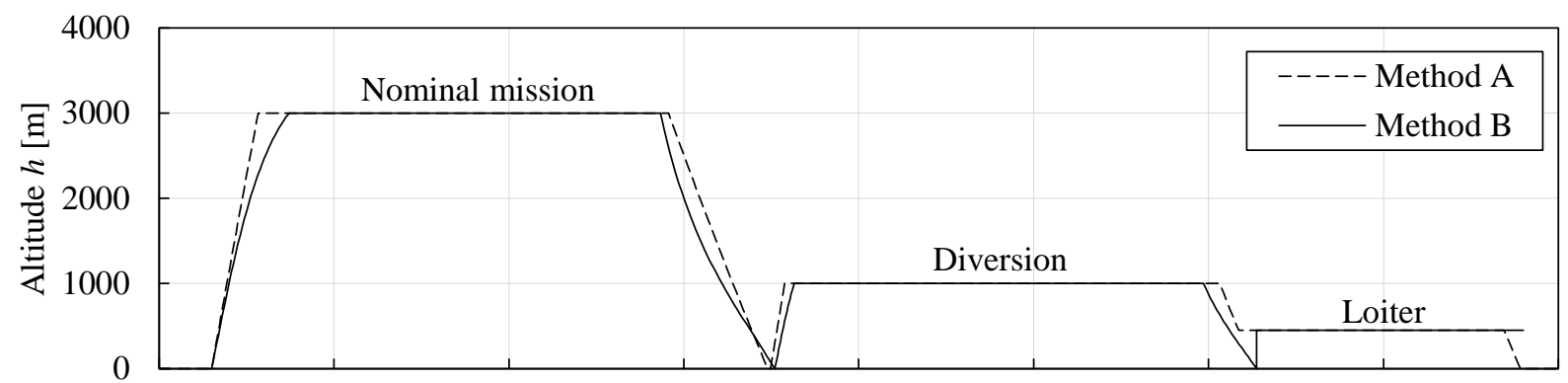

a) Altitude profile

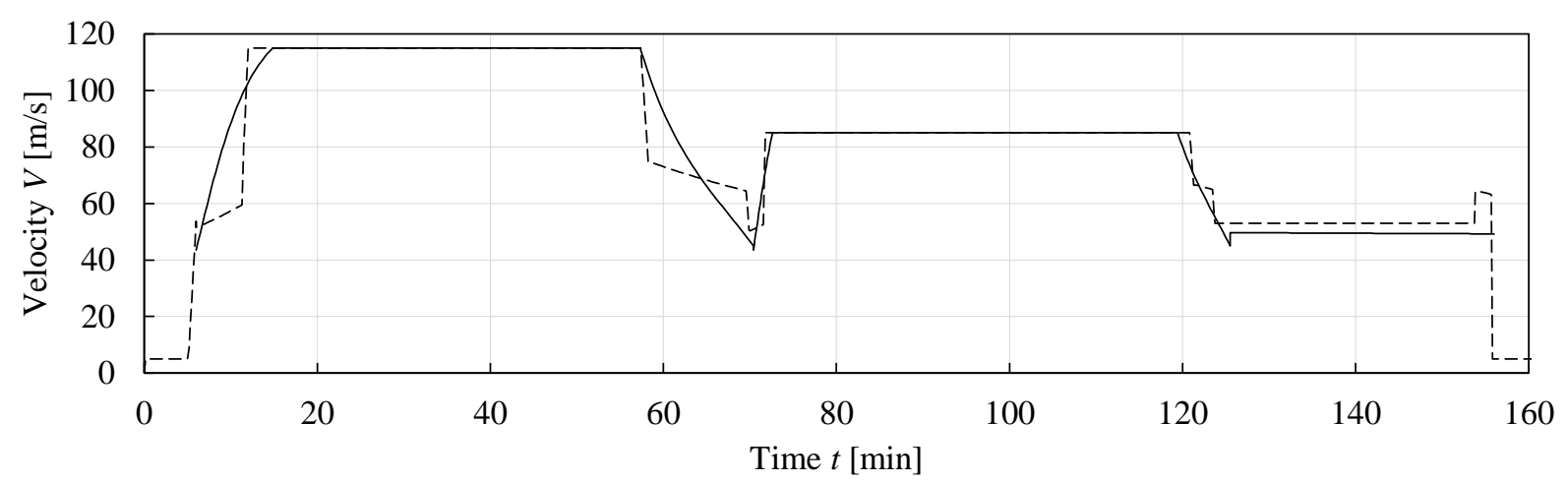

b) Velocity profile

Fig. 10 Reference aircraft altitude (top) and velocity (bottom) profiles for the short-range mission.

\section{Turboprop Engines}

For the comparison of (hybrid-) electric concepts, the thermal efficiency of the gas turbines is fixed, independently of the throttle setting or flight condition, and assumed to be $\eta_{\mathrm{GT}}=0.2112$ This corresponds to a BSFC of $398 \mathrm{~g} / \mathrm{kWh}$, and is applied to both the (hybrid-) electric concepts and the conventional fuel-based reference aircraft, which is reevaluated for this comparison. This value is obtained by calculating the average efficiency of the short-range mission, including the ground and diversion phases of the mission. Finally, the mass of the gas turbines is estimated using the specific power $P_{\mathrm{GT}}^{*}=3.31 \mathrm{~kW} / \mathrm{kg}$ of the Do 228 's flat-rated TPE331 turboprop engines

\section{Electric Motors}

The values of specific power and transmission efficiency assumed for the electrical machines (EM) and inverters/rectifiers are based on the state-of-the-art research goals presented in Ref. [52] and are gathered in Table 7. The EMs are assumed to achieve $13 \mathrm{~kW} / \mathrm{kg}$, and the specific power of the power converters is assumed to be $19 \mathrm{~kW} / \mathrm{kg}$. Since a thermal management system and additional elements of the power management and distribution (PMAD) system can significantly increase this system's mass, the total mass of the electrical systems is increased by $30 \%$. This generic mass penalty is assumed due to a lack of information in the preliminary sizing phase for an accurate estimation of the mass of components such as cooling systems or cables. Thus, the equivalent specific EM mass is assumed to be $5.92 \mathrm{~kW} / \mathrm{kg}$. To describe the losses of the entire electrical system, a constant equivalent motor efficiency of $95 \%$ is used, and all other component's efficiencies are set to $100 \%$.

\section{Battery System}

The battery system is modeled using a rudimentary "energy in a box" approach. Thus, an idealized constant potential battery is assumed. The internal resistance and other losses are assumed to be zero, and consequently, the efficiency of the battery is $100 \%$ (see Table 7). To preserve battery life and to account for energy reserves, a $20 \%$ state-of-charge margin is used. For the sake of comparison, futuristic technology assumptions are used, to allow for convergence of aircraft with high levels of hybridization and fully electric aircraft. With a specific energy $E_{\text {bat }}^{*}=1500 \mathrm{Wh} / \mathrm{kg}$ and a $4 \mathrm{C}$ discharge rate, reasonable MTOM values could be achieved. The selection of more realistic, near term battery technology would have resulted in too many unconverged design points. As the absolute results are of minor interest 
for this comparative study, the authors preferred to select $E_{\text {bat }}^{*}$ values, which allow for extensive parameter sweeps and comparisons. However, it is important to note that the technology values assumed for the batteries at pack level $\left(E_{\mathrm{bat}}^{*}=1500 \mathrm{Wh} / \mathrm{kg}\right.$ and $\left.P_{\mathrm{bat}}^{*}=6 \mathrm{~kW} / \mathrm{kg}\right)$ must be considered beyond optimistic. The maximum theoretical specific energy of Li-Ion batteries at cell level is $700 \mathrm{Wh} / \mathrm{kg}$. Lithium-sulfur or aluminum-air batteries could reach such high specific energy levels in theory but are far from being usable in practical, high-power applications.

\section{Mission Modelling}

For conventional 19-seater aircraft, a 5\% contingency fuel reserve has to be maintained [43]. Given that for HEP aircraft it is unclear whether these energy reserves should be accounted for in the fuel energy, battery energy, or both, this $5 \%$ contribution to total energy is not included in the following analyses. Thus, the fuel mass is reduced compared to the conventional short-range results.

Table 7 Characteristics assumed for powertrain components.

\begin{tabular}{lclc}
\hline \hline Parameter & Value & Parameter & Value \\
\hline Turboshaft specific power $P_{\mathrm{GT}}^{*}[\mathrm{~kW} / \mathrm{kg}]$ & 3.31 & Battery specific energy $E_{\mathrm{bat}}^{*}[\mathrm{Wh} / \mathrm{kg}]$ & 1500 \\
Turboshaft efficiency $\eta_{\mathrm{GT}}[-]$ & $21.1 \%$ & Battery specific power $P_{\mathrm{bat}}^{*}[\mathrm{~kW} / \mathrm{kg}]$ & $6.0(=4 C)$ \\
$\begin{array}{l}\text { Electrical machine specific power } \\
\text { (equivalent) } P_{\mathrm{EM}}^{*}, P_{\mathrm{GEN}}^{*}[\mathrm{~kW} / \mathrm{kg}]\end{array}$ & 5.92 & Battery efficiency $\eta_{\mathrm{bat}}[-]$ & $100 \%$ \\
$\begin{array}{l}\text { Electric machine efficiency } \\
\text { (equivalent) } \eta_{\mathrm{EM}}, \eta_{\mathrm{GEN}}[-]\end{array}$ & $95 \%$ & Minimum state-of-charge [-] & $20 \%$ \\
\hline
\end{tabular}

\section{B. Comparison of Baseline Missions}

In this section, the HEP variants are sized for the three reference missions presented in Sec III.A. Both methods differ in their approach to constructing the matching diagram, which is the first step of the sizing process. This is not only true with regards to the determination of the constraint lines, as discussed in Sec. III, but also with respect to the determination of the power split of the components of the hybrid-electric powertrain. To illustrate the difference, Fig. 11 presents a series of matching diagrams obtained from Method A and Method B. For both methods, only the five driving constraints (as discussed in Sec. III) are presented; other constraints from the certification specifications are neglected. As this example is only meant to further illustrate the different approaches of the methods, the matching diagrams are only shown for the parallel-hybrid propulsion architecture.

Method A attempts to simplify the matching process as much as possible. This allows using a graphical method to assess the hybrid electric design space. The results for any required figure of merit (e.g. MTOM, energy usage, or cost) can then be plotted and superimposed to the performance constraints. Such figures are sometimes called "thumbprint plots" and can be used to understand the hybrid-electric design space and select the best design point. More information can be found in Ref. [21]. However, finding a "best" design point is not the objective of this comparative study. Therefore, only a basic approach is explained: the constraint diagram is constructed, corrected to maximum throttle at sea level, as well as maximum take-off mass, and subsequently, the design point is selected. In Fig. 11, the design point is $18.63 \mathrm{~W} / \mathrm{N}$ at a wing loading of $1.96 \mathrm{kN} / \mathrm{m}^{2}$. To find the power required for a predetermined hybridization ratio, the total power-to-weight ratio, $P / W_{\mathrm{TO}}$, is split by the hybridization ratio. For the example in Fig. 11 , a $P / W_{T O}$ of $16.76 \mathrm{~W} / \mathrm{N}$ is selected for the gas turbine, while the remaining difference between gas turbine power and total installed power is provided by the electric power system. In other words, a hybridization of $10 \%$ is used, and thus $P_{\mathrm{GT}} / W_{\mathrm{TO}}=16.76$, and $P_{\mathrm{EM}} / W_{\mathrm{TO}}=1.87$. Because the normalization to maximum throttle at sea level is carried out before the power is split, the electric powertrain components are slightly oversized.

Method B, on the other hand, allows the designer to specify different power-control parameters (i.e., throttle and supplied power ratio) for each performance constraint. Hence, different components can be sized by different constraints, and none of the components is over-sized. For example, if the batteries and electromotor were only used during climb, then they would be actively sized in that condition, while the gas-turbine would have to provide only part-power, and would, therefore, be sized by a different constraint such as take-off or cruise. However, compared to Method A, this requires the designer to specify additional control settings, leading to a more complex interpretation of the matching diagrams, as evidenced in the bottom half of Fig. 11. This figure shows how first the shaft-power matching diagram is constructed (Fig. 11.B.1), based on which the matching diagrams of the remaining elements of the powertrain (see Fig. 4) are computed for a given power split. Since the power split is kept constant for all performance constraints in this study $\left(H_{\mathrm{p}}=0.1\right)$, the relative positions of the constraints do not change much, although 

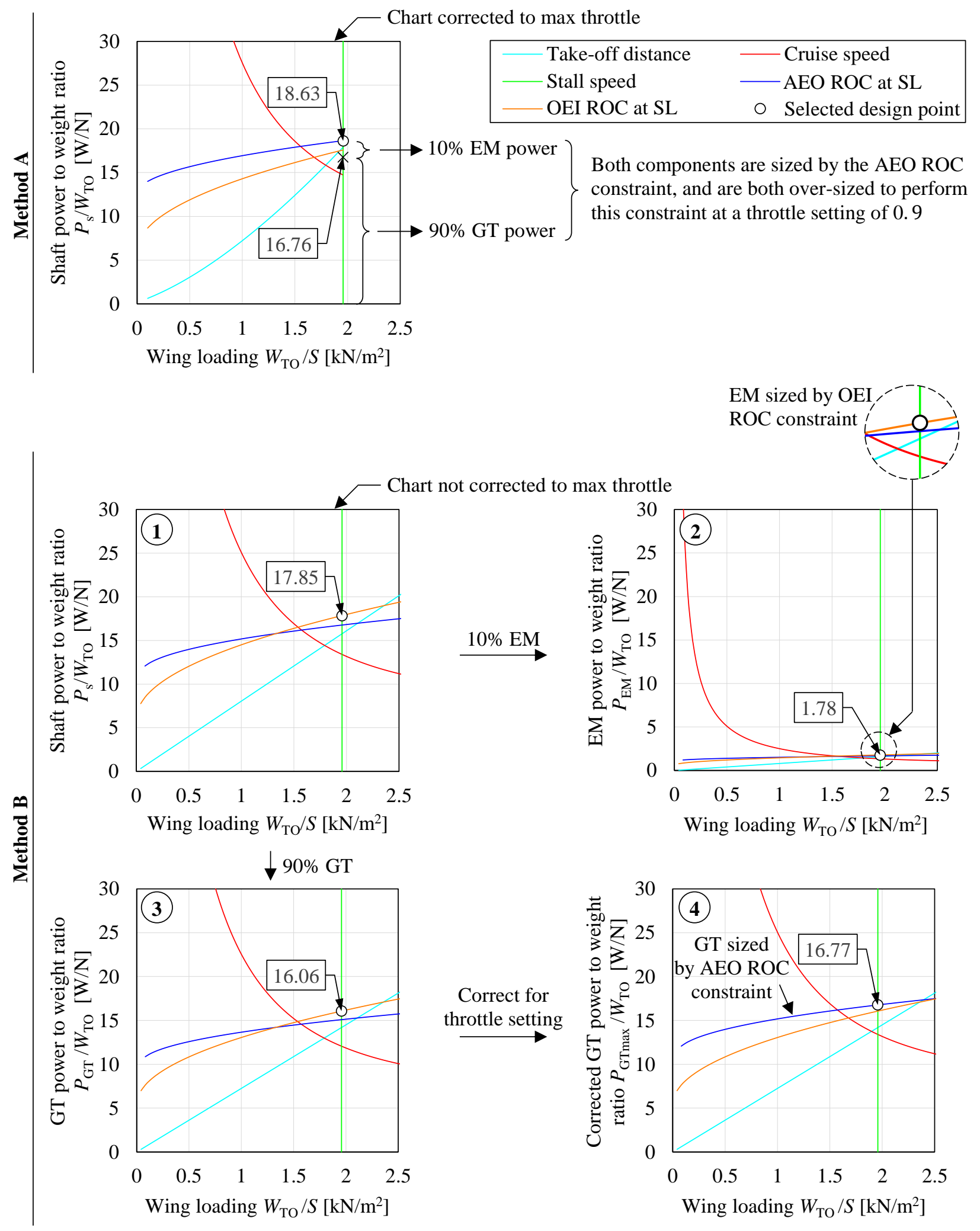

Fig. 11 Overview of how the constraint diagrams of Method A (top) and Method B (bottom) are used in the design process. Diagrams obtained for the parallel powertrain configuration. 
the power-to-weight ratio required from the electric motors is much lower than the gas turbine, as visible in Figs. 11.B.2 and 11.B.3. Given that different throttle settings are used for different constraints (see Table A.2), the gas turbine has a different active constraint than the electric motors. Note that only the gas turbine is corrected for throttle setting, as shown in Fig. 11.B.4. Nevertheless, even though the two methods use fundamentally different approaches for the matching diagrams, the resulting design points are comparable. The gas-turbine power-to-weight ratio is virtually the same for both cases $\left(P_{\mathrm{GT}} / \mathrm{W}_{\mathrm{TO}}=16.76\right.$ and 16.77 for methods $\mathrm{A}$ and $\mathrm{B}$, respectively). The power-toweight ratio obtained for the electrical motors is approximately $5 \%$ lower for Method $\mathrm{B}\left(P_{\mathrm{EM}} / W_{\mathrm{TO}}=1.87\right.$ and 1.78 for methods $\mathrm{A}$ and $\mathrm{B}$, respectively) since it is not throttle-corrected.

Using the $P / W_{T O}$ and $W_{T O} / S$ data from the constraint diagrams, the mission performance analysis is then carried out, and the aircraft's size is matched to the required mission performance. The resulting MTOM predicted by the two methods is presented in Table 8, including the difference of Method B with respect to Method A, which is calculated by $\left(\mathrm{MTOM}_{\mathrm{B}}-\mathrm{MTOM}_{\mathrm{A}}\right) / \mathrm{MTOM}_{\mathrm{A}}$. Additionally, the MTOM breakdown obtained for the short-range mission is shown in Fig. 12. In all cases, the differences between the two methods are well within the uncertainty of a Class-I sizing process. The most important conclusions that can be drawn are summarized in the following paragraphs.

Table 8 Maximum-take off mass values calculated for the conventional, parallel, serial, and fully-electric powertrain configurations using the two sizing methods. "N/A" indicates that no converged design was obtained.

\begin{tabular}{cccccc}
\hline \hline Powertrain & Range [km] & Payload [t] & $\begin{array}{c}\text { Method A } \\
\text { MTOM [t] }\end{array}$ & $\begin{array}{c}\text { Method B } \\
\text { MTOM [t] }\end{array}$ & Difference [\%] \\
\hline \multirow{3}{*}{ Conventional } & 396 & 1.96 & 6.22 & 6.26 & $+0.7 \%$ \\
& 1280 & 1.33 & 6.36 & 6.45 & $+1.3 \%$ \\
& 2361 & 0.55 & 7.08 & 7.18 & $+1.4 \%$ \\
\hline \multirow{3}{*}{ Parallel } & 396 & 1.96 & 6.36 & 6.39 & $+0.4 \%$ \\
& 1280 & 1.33 & 7.06 & 7.10 & $+0.6 \%$ \\
& 2361 & 0.55 & 13.47 & 13.36 & $-0.8 \%$ \\
\hline \multirow{3}{*}{ Serial } & 396 & 1.96 & 8.30 & 8.25 & $-0.6 \%$ \\
& 1280 & 1.33 & 12.52 & 12.35 & $-1.3 \%$ \\
& 2361 & 0.55 & N/A & N/A & N/A \\
\hline \multirow{3}{*}{ Electric } & 396 & 1.96 & 8.17 & 8.29 & $+1.5 \%$ \\
& 1280 & 1.33 & N/A & N/A & N/A \\
& 2361 & 0.55 & N/A & N/A & N/A \\
\hline \hline
\end{tabular}

1. Conventional Powertrain

The results for the conventional powertrain configuration (shown in Table 8) differ slightly from the results shown in Sec. III, due to the simplified modeling approach taken for the HEP comparison. The discrepancy is larger for the short- and long-range missions than for the medium-range mission. For both methods, the MTOM obtained for the short-range mission is lower than in Sec. III, because the average gas-turbine efficiency is accurate, but the fuel reserves are neglected. The MTOM obtained for the long-range mission, to the contrary, is over-predicted because, in this case, the exclusion of contingency fuel has a relatively lower impact, while the assumed gas-turbine efficiency is lower than in practice, due to the long cruise segment. Nevertheless, the agreement between both methods is good. The maximum difference in MTOM between method A and method B is less than $1.5 \%$.

\section{Parallel-Hybrid Powertrain}

The results for the parallel hybrid powertrain (compare Fig. 4) show excellent agreement, with a difference of less than $1 \%$ between both methods. For both the parallel-hybrid and the serial-hybrid designs, the level of hybridization is fixed at $10 \%$. For the parallel-hybrid, this means that the propeller is always supplied by 1 part electric motor power and 9 parts gas turbine power, joined through a gearbox with $100 \%$ efficiency. A converged design is obtained for all three missions, even though the long-range aircraft is more than twice as heavy as the short-range aircraft. Considering the very advanced technology assumptions that are made, this result indicates that efficient long-range flying with hybrid-electric propulsion systems is not a straightforward task. However, the detailed results for the short-range mission (Fig. 12) show that the fuel mass is reduced, when comparing against the conventional propulsion layout, even though MTOM increases. 


\section{Serial-Hybrid Powertrain}

For this study, none of the prospective advantages (aero-propulsive interaction, distributed propulsion, etc.) of serialhybrid designs are taken into account. The serial-hybrid powertrain is therefore expected to perform worse (heavier, less efficient) than the conventional or parallel-hybrid configurations. This is supported by the results presented in Table 8. Only the short- and medium-range mission have converged. For the long-range mission, the powertrain is too heavy and inefficient to converge - even with the highly optimistic technology assumptions. The results are very close ( $0.6 \%$ difference) for the short-range mission, and still provide an acceptable agreement (1.6\% difference) for the medium-range mission. It is worth noting that, just as for the parallel-hybrid powertrain, the level of hybridization is fixed at $10 \%$. This means that the electric motor is always supplied by 1 part battery power and 9 parts generator power.

\section{Fully Electric Powertrain}

The final analysis is conducted for the fully electric powertrain configuration. Even with the highly optimistic technology assumptions, only the short-range mission converges for this powertrain architecture, as shown in Table 8. The medium and long-range missions require an MTOM above 50 tons, which is infeasible for a 19-seat aircraft. Yet, both methods converged within $1.5 \%$ for the short-range mission. For this specific set of requirements and technology assumptions, the serial-hybrid short-range aircraft and the electric short-range aircraft converge to almost the same MTOM. In Fig. 12 it can be observed that the additional mass required by the batteries for the fully-electric configuration completely compensates the weight reduction due to the absence of gas turbines, fuel, and generators. However, while Method A predicts a higher MTOM than Method B for the serial-hybrid short-range case, it predicts a lower MTOM for the electric short-range case. Therefore, no clear conclusion can be drawn regarding which of the two methods is more (or less) conservative.

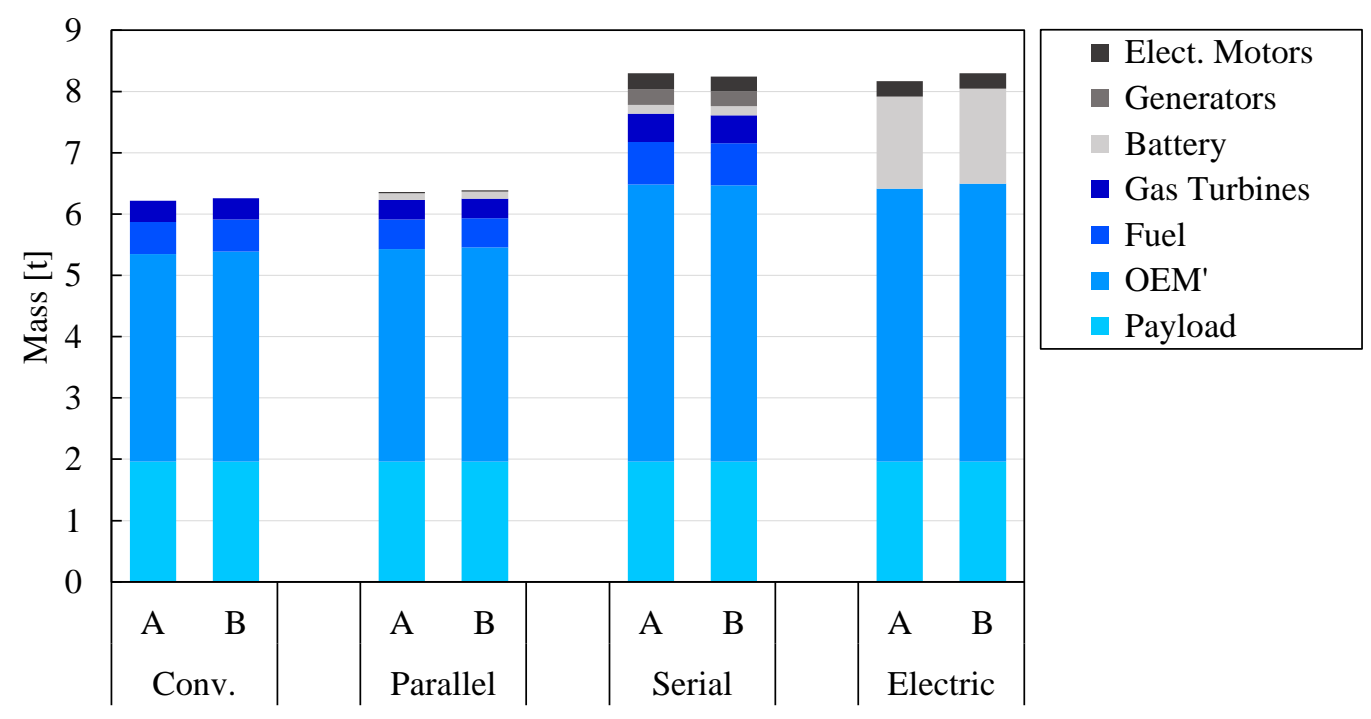

Fig. 12 Mass breakdown of the four powertrain configurations obtained using Method A and Method B, for the shortrange mission $\left(R=396 \mathrm{~km}, m_{\mathrm{PL}}=1.96 \mathrm{t}\right)$.

\section{Parameter Sweeps}

As a final step of this validation study, the design methods are evaluated regarding their ability to properly account for changes in the technology level and TLARs. The reader is reminded that the aim is to compare the data and gradients obtained with the two methods, and not to study the impact of these parameters on the resulting aircraft's design. In this process, the impact of three parameters is analyzed: range, battery specific energy, and the hybridization ratio. The baseline point for the parameter sweeps is the short-range mission. Thus, payload is fixed at $1.96 \mathrm{t}$, and the design range is fixed at $396 \mathrm{~km}$. The baseline technology assumptions are the same as in Sec. IV.B, $\left(E_{\text {bat }}^{*}=1500\right.$ $\mathrm{Wh} / \mathrm{kg}$ and $H_{\mathrm{P}}=0.1$ ). Mission range is swept between $100 \mathrm{~km}$ and $2500 \mathrm{~km}$, battery specific energy is swept between $100 \mathrm{Wh} / \mathrm{kg}$ and $2000 \mathrm{Wh} / \mathrm{kg}$, and the hybridization ratio is varied between 0 and 1 , all while maintaining the remaining parameters constant. 
The results for the parameter sweeps are analyzed for two measures of merit: MTOM and PREE. MTOM is often used for comparison in aircraft design studies since it gives an indication of the "size" of the aircraft and has a direct impact on power requirements, energy requirements, production and maintenance costs, and the certification of the aircraft [9]. The Payload-Range Energy Efficiency (PREE) [32], meanwhile, is used as the figure of merit to evaluate the energy consumption of the aircraft. The PREE is defined as payload weight times the range of the aircraft, divided by the total energy consumed during the nominal mission (excluding reserves), i.e.:

$$
\text { PREE }=\frac{W_{\mathrm{PL}} \cdot R}{E_{\mathrm{miss}}}
$$

Therefore, this dimensionless parameter indicates how efficiently the aircraft can transport its payload over a determined distance during its day-to-day operation. In Eq. 7, the energy consumed during the nominal mission, $E_{\text {miss }}$, is calculated differently by the two methods:

$$
\begin{gathered}
E_{\text {miss }, \mathrm{A}}=E_{\text {taxi out }}+E_{\mathrm{TO}}+E_{\text {climb }}+E_{\text {cruise }}+E_{\text {descent }} \\
E_{\text {miss }, \mathrm{B}}=E_{\text {taxi out }}+E_{\mathrm{TO}}+E_{\text {climb }}+E_{\text {cruise }}+E_{\text {descent }}+E_{\text {landing }}+E_{\text {taxi in }}
\end{gathered}
$$

While Method B uses energy fractions that are known a priori for taxi, take-off, and landing (see Table A.5), Method A specifically calculates the energy consumption in these phases. The landing phase and the taxi-in phase are analyzed after flying the diversion. Thus, these phases would be analyzed at a wrong mass. To avoid confusion, these phases were entirely disregarded for the calculation of $E_{\text {miss. }}$ Thus, $E_{\text {miss }}$ will be slightly lower for Method A than for Method $B$, resulting in higher PREE values. Nevertheless, the difference was confirmed to be minor.

The following subsections detail the three parameter sweeps separately. Data for these comparisons are provided in the appendix so that these trade studies can be used as reference cases for benchmarking and validation of other design tools.

\section{Range}

The design range is varied from $100 \mathrm{~km}$ to $2500 \mathrm{~km}$. Thus, short-range missions of just $15 \mathrm{~min}$ flight time are covered at the low end, while the longest flight would last 6 hours. Range is swept in steps of $100 \mathrm{~km}$, and the results of the sweep are presented in Fig. 13.

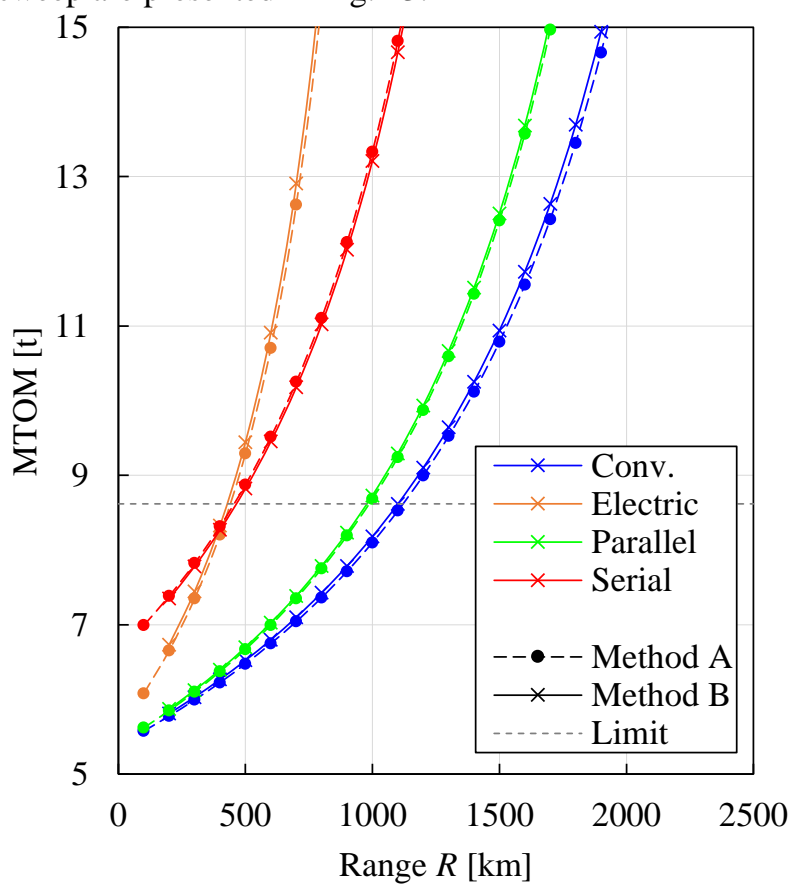

a) Maximum take-off mass

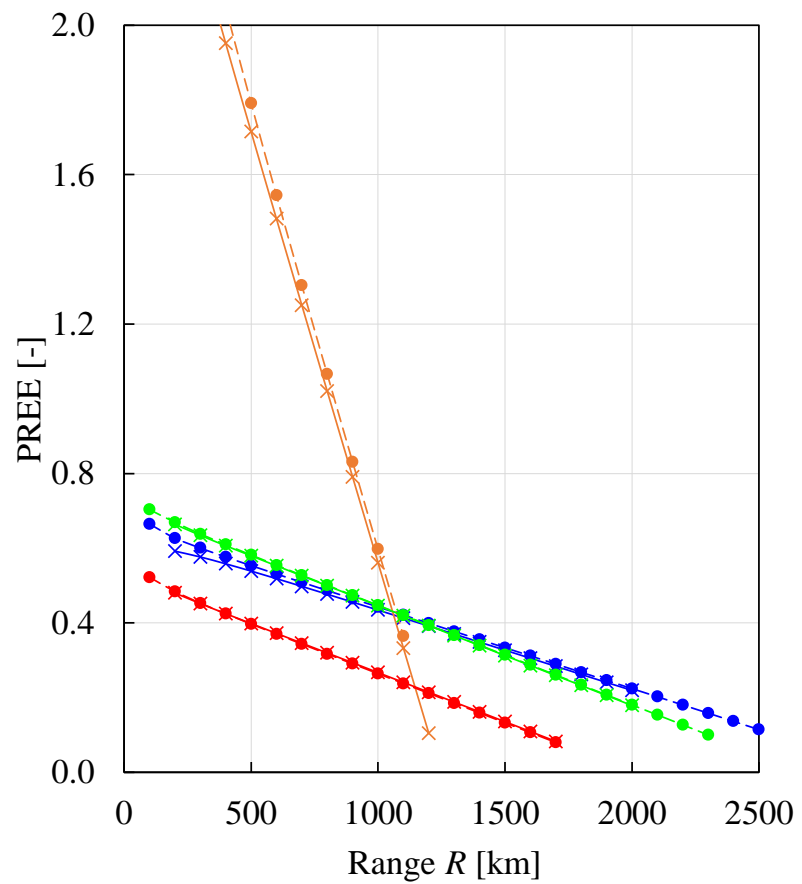

b) Payload-range energy efficiency

Fig. 13 Maximum take-off mass and PREE obtained for different mission ranges $\left(E_{\text {bat }}^{*}=1500 \mathrm{Wh} / \mathrm{kg}, H \mathrm{P}=0.1\right)$. The gray dashed line indicates the MTOM limit for a 19-passenger commuter aircraft per CS-23 regulations. 
Both plots - MTOM, as well as PREE - correlate very well. All basic trends are captured. The MTOM plots show an exponential relationship for increasing ranges. The PREE plots drop almost linearly, as longer flights are analyzed. When analyzing MTOM results, the conventional aircraft shows to be less sensitive to an increase in range, when compared to the other designs. The serial and parallel designs show a similar slope but present an offset. This can be attributed to the mass increase, which is inherent to the hybrid propulsion systems. The fully electric design shows the highest slope. This behavior is expected, due to the much lower specific energy of batteries, compared to fossil fuels.

PREE shows an almost linear relationship with range. Again, the highest sensitivity is observed for the fully electric aircraft, and the lowest sensitivity is observed for the conventional design. This corresponds with the data of the MTOM analysis. When results for methods A and B are compared, they show only subtle differences for PREE. Method A always slightly overpredicts PREE. This is expected, because the energy summation is slightly different between the methods, as described previously. The difference is more pronounced at the lower ranges because the relative time spent for landing and taxi in is decreasing, as total flight time is increased. Therefore, the error is less relevant at long ranges.

If the CS-23 commuter mass limit of $8618 \mathrm{~kg}(19000 \mathrm{lb})$ would be enforced, then the maximum range of the fully electric and serial hybrid designs would be limited to less than $450 \mathrm{~km}$, while the conventional aircraft could achieve ranges of $1100 \mathrm{~km}$, more than twice as far. However, even though the conventional aircraft is the lightest, its PREE is inferior to the electric and parallel hybrid design at ranges up to $1100 \mathrm{~km}$. This shows the general trend that electric and hybrid-electric aircraft can be more efficient for short-distance flights, while longer ranges are most likely to be carried out by conventional aircraft. However, these are unoptimized designs with extremely optimistic technology assumptions, and thus no quantitative conclusions should be drawn from this data.

\section{Battery Technology Level}

The specific energy $E_{\mathrm{bat}}^{*}$ of the batteries is varied from $100 \mathrm{Wh} / \mathrm{kg}$ to $2000 \mathrm{Wh} / \mathrm{kg}$. At the same time, the specific power $P_{\text {bat }}^{*}$ is varied to maintain a constant discharge rate of $4 \mathrm{C}$. Thus, $P_{\text {bat }}^{*}=0.4 \mathrm{~kW} / \mathrm{kg}$ at $100 \mathrm{Wh} / \mathrm{kg}$, while $P_{\text {bat }}^{*}=$ $8 \mathrm{~kW} / \mathrm{kg}$ at $2000 \mathrm{Wh} / \mathrm{kg}$. $E_{\mathrm{bat}}^{*}$ is varied in steps of $100 \mathrm{Wh} / \mathrm{kg}$, and the results of the sweep are presented in Fig. 14. For the $4 \mathrm{C}$ discharge rate assumed, the battery mass was found to be sized by energy requirements in all cases, and not by power requirements. Thus, all missions are terminated with a $20 \%$ state-of-charge.

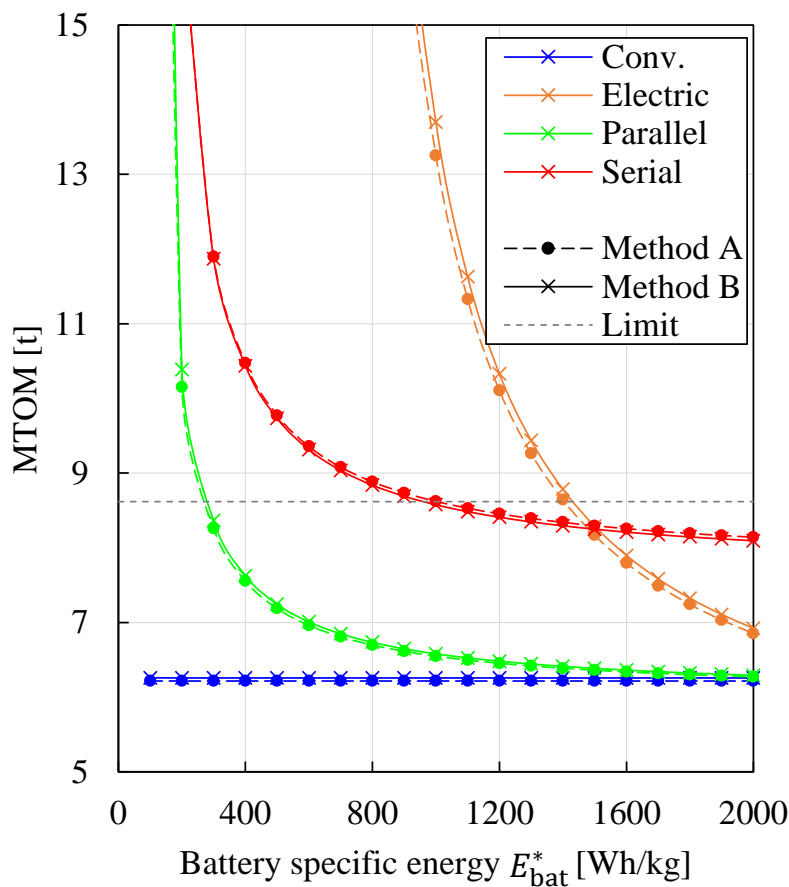

a) Maximum take-off mass

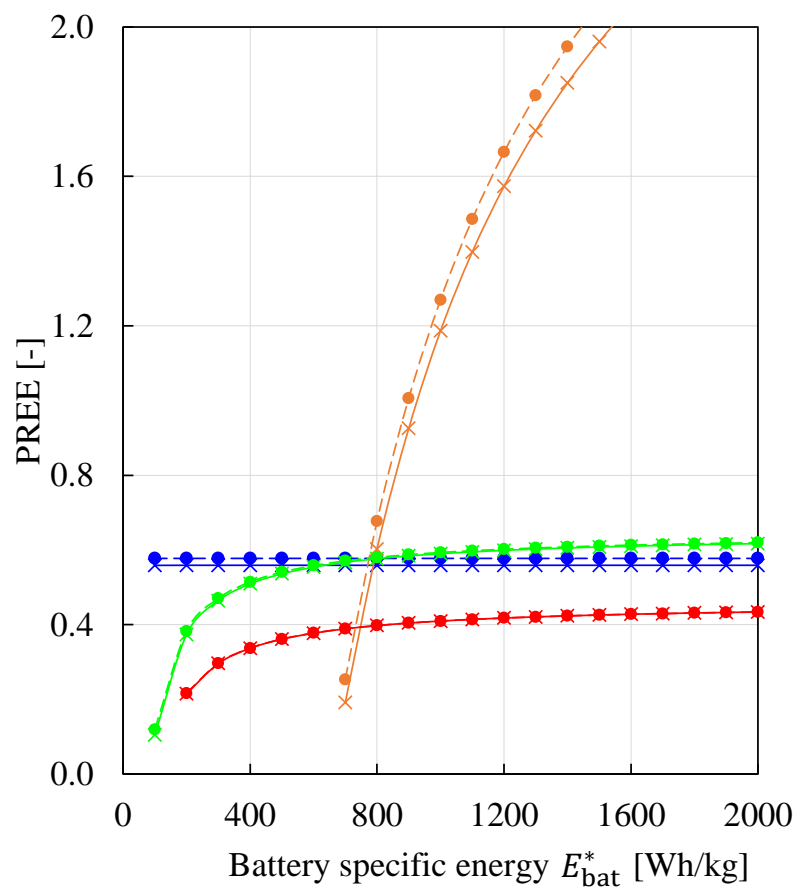

b) Payload-range energy efficiency

Fig. 14 Maximum take-off mass and PREE obtained for different battery technology levels $(R=396 \mathrm{~km}, H \mathrm{P}=0.1)$. The gray dashed line indicates the MTOM limit for a 19-passenger commuter aircraft per CS-23 regulations. 
Again, the MTOM and PREE plots show very good correlation for all propulsion architectures. The expected trends are captured, with battery technology having no influence on conventional designs. For the remaining configurations, improving battery performance will yield lighter aircraft, which will be more efficient. Thus, for this study, PREE is roughly inversely proportional to MTOM. The absolute differences in MTOM between methods A and $\mathrm{B}$ are more pronounced at lower technology levels because the aircraft become heavier.

Method A again slightly over-predicts PREE, when compared to Method B. For this analysis, the relative error of the PREE calculation remains nearly constant across the sweep, because the mission is not varied. The difference in PREE is more evident for the fully electric configuration (approximately $5 \%$ for the baseline $E_{\text {bat }}^{*}=1500 \mathrm{Wh} / \mathrm{kg}$ ) and is also reflected in the MTOM comparison. This discrepancy is more prominent for the fully-electric configuration due to the higher battery weight fraction and subsequent higher sensitivity to battery specific energy.

Figure 13 shows that the CS-23 mass limit requires an $E_{\mathrm{bat}}^{*}$ of at least $1450 \mathrm{Wh} / \mathrm{kg}$ to allow for a fully-electric design. This indicates that electric propulsion systems will not be a drop-in replacement for conventional propulsion systems in the near future. However, a design with such kind of batteries would reach three times the PREE of the conventional aircraft. Benefits in terms of PREE can already be observed for batteries that exceed $800 \mathrm{Wh} / \mathrm{kg}$. However, these aircraft would be four times heavier than comparable conventional aircraft, due to the snowball effect of the sizing process. Finally, Fig. 14 also shows that parallel architectures can present minor improvements in PREE if the battery specific energy is increased beyond $700 \mathrm{Wh} / \mathrm{kg}$. Serial powertrains, on the other hand, are always outperformed by conventional fuel-based powertrains, since no hypothetical improvements in aero-propulsive efficiency or gas-turbine efficiency are included in this study.

\section{Hybridization ratio}

The hybridization ratio of the propulsion system is varied from $0 \%$ to $100 \%$ in steps of $10 \%$. Note that the hybridization ratio is defined differently for serial and parallel powertrains, as discussed in Sec. II.C. In both cases, a hybridization ratio of $100 \%$ corresponds to a fully electric aircraft, which exclusively uses batteries. However, for a serial architecture, a hybridization of $0 \%$ corresponds to a turboelectric aircraft, while for a parallel architecture, the powertrain is reduced to a conventional fuel-based engine. Consequently, Fig. 15 shows the results of the parameter sweeps for the serial and parallel powertrains, while the conventional and fully-electric configurations are obtained as limit cases of these two sweeps.

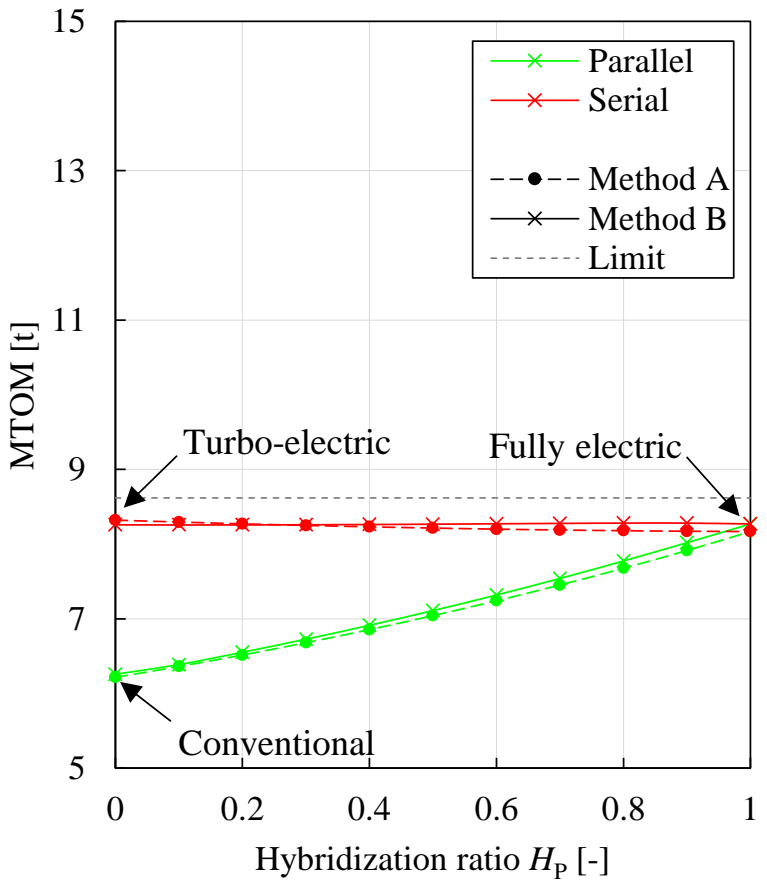

a) Maximum take-off mass

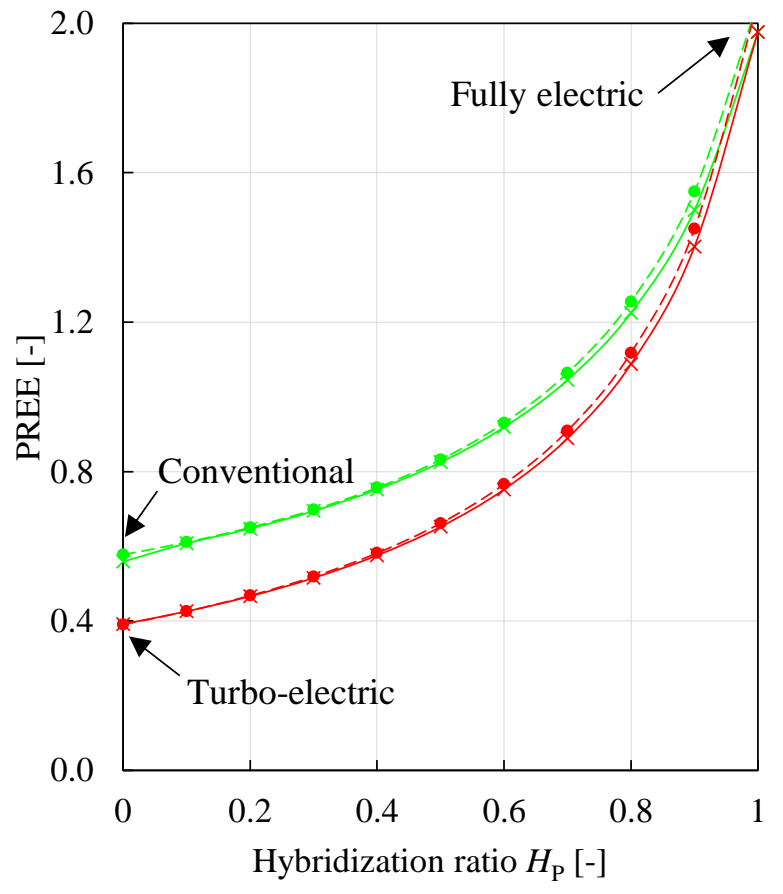

b) Payload-range energy efficiency

Fig. 15 Maximum take-off mass and PREE obtained for different hybridization ratios $\left(R=396 \mathrm{~km}, E_{\mathrm{bat}}^{*}=1500\right.$ $\mathrm{Wh} / \mathrm{kg}$ ). The gray dashed line indicates the MTOM limit for a 19-passenger commuter aircraft per CS-23 regulations. 
Once more, the MTOM and PREE plots show a very good correlation between the methods for both propulsion architectures. The parallel hybrid with a hybridization ratio of $0 \%$ corresponds to a conventional aircraft and is, therefore, the lightest solution for the given mission. As the hybridization ratio is increased, the relative size of the electric power systems of the aircraft increase. However, as MTOM increases, so does PREE. At 100\% hybridization the fully electric configuration is reached. The data points, at $H_{\mathrm{P}, \mathrm{PH}}=0.0,0.1$, and 1.0 can also be found in the previous diagrams. The serial hybrid with a hybridization of $0 \%$ corresponds to a turbo-electric propulsion configuration which uses no buffer battery. As $H_{\mathrm{P}, \mathrm{SH}}$ increases, the gas turbine size is reduced, and batteries are added, until the fully electric configuration is reached at $H_{\mathrm{P}, \mathrm{SH}}=1.0$.

Figure 14a shows that MTOM is practically insensitive to the hybridization ratio, while PREE improves with increasing hybridization. The authors suspected that this almost constant relationship between $H_{\mathrm{P}}$ and MTOM is specific for this set of input parameters, and not a trend inherent to the type of propulsion system in general. To confirm this hypothesis, the hybridization sweep of the serial hybrid architecture was also conducted for batteries with a specific energy of $3000 \mathrm{Wh} / \mathrm{kg}$. The results are not shown here, but for that case, MTOM was found to vary significantly with the level of hybridization. Therefore, the lack of a gradient is a coincidence. For the selected input parameters, the increase in battery mass as $H_{\mathrm{P}}$ increases compensates the decrease in engine, generator, and fuel mass.

\section{Conclusions}

In this study, two preliminary sizing methods for hybrid-electric aircraft are compared in detail. The two methods, developed at FH Aachen and TU Delft, respectively, are used to evaluate a 19-passenger commuter aircraft. The fuelbased reference aircraft is first sized for three points of the payload-range diagram. The results obtained from the two methods deviate from the reference data by approximately $1 \%$ in terms of power-to-weight ratio, and by less than $4 \%$ in terms of maximum take-off mass (MTOM). The discrepancy in MTOM is predominantly attributed to uncertainties in component modeling and variations in the mission profile.

The two methods are then used to evaluate parallel, serial, and fully-electric configurations. When comparing the different powertrain architectures for the three payload-range combinations selected, a difference in MTOM of less than $2 \%$ is observed between the two methods. Additionally, three parameter sweeps are performed, in order to analyze the sensitivity of MTOM and Payload-Range Energy Efficiency (PREE) to mission range, battery specific energy, and the hybridization ratio of the aircraft. The results of these sweeps show an excellent agreement in both slope and offset between the two methods. The largest deviations are observed for the fully-electric configuration, due to the sensitivity of the battery-weight fraction to energy consumption. This leads to a PREE difference between the two methods of approximately $5 \%$ for the baseline mission requirements and technology assumptions.

These differences observed lie well within the uncertainty of the Class-I sizing process and confirm the correct implementation of the two methods. Although this does not necessarily guarantee that the formulation of the methods is flawless - since both methods might coincidentally be based on the same, inaccurate assumption - the agreement of results significantly increases the confidence in these two formulations. This is further evidenced by the trends observed in the parameters sweeps, which coincide with those expected from literature. Moreover, throughout this study, the differences between the two methods are exposed as much as possible, such that the results can be used as a benchmark by the aircraft design community to compare and validate other design methods for hybrid-electric aircraft.

\section{Acknowledgments}

The authors would like to thank Maurice Hoogreef for helping with the evaluation of CS-23 requirements. The authors also thank Falk Götten, who provided valuable guidance on the set-up of the CFD simulation. Finally, the authors like to express their gratitude to Siemens PLM Software for providing academic licenses of their software StarCCM+. 


\section{References}

[1] Wilberforce, T., El-Hassan, Z., Khatib, F. N., Al Makky, A., Baroutaji, A., Carton, J. G., and Olabi, A. G., "Developments of Electric Cars and Fuel Cell Hydrogen Electric Cars," International Journal of Hydrogen Energy, pp. 25695-25734, 5 October 2017.

https://doi.org/10.1016/j.ijhydene.2017.07.054

[2] De Breucker, S., Peeters, E., and Driesen, J., "Possible Applications of Plug-In Hybrid Electric Ships," in 2009 IEEE

Electric Ship Technologies Symposium, IEEE Publ., Piscataway, NJ, 2009, pp. 310-317. https://doi.org/10.1109/ESTS.2009.4906530

[3] Hepperle, M., "Electric Flight-Potential and Limitations," NATO MPAVT-209-09, Energy Efficient Technologies and Concepts of Operation, Lisbon, Portugal, Oct. 2012.

[4] Warwick, G., "Electric Potential - Are battery technologies advancing fast enough to enable eVTOL," Aviation Week \& Space Technology, pp. 38-41, 14 August 2017.

[5] Brelje, B. J., and Martins, J. R. R. A., "Electric, Hybrid, and Turboelectric Fixed-Wing Aircraft: A Review of Concepts, Models, and Design Approaches," Progress in Aerospace Sciences, Vol 104, pp. 1-19, 2018. https://doi.org/10.1016/j.paerosci.2018.06.004

[6] Moore, M. D., and Fredericks, B., "Misconceptions of Electric Propulsion Aircraft and their Emergent Aviation Markets," in 52nd Aerospace Sciences Meeting, National Harbor, MD, USA, 2014. https://doi.org/10.2514/6.2014-0535

[7] Friedrich, C., and Robertson, P. A., "Hybrid-Electric Propulsion for Aircraft," Journal of Aircraft, pp. 176-189, February 2015. https://doi.org/10.2514/1.C032660

[8] Raymer, D. P., Aircraft Design: A Conceptual Approach, 6th ed., Reston, VA, USA: AIAA, 2018.

[9] Nicolai, L. M. and Carichner, G. E., Fundamentals of Aircraft and Airship Design - Volume I - Aircraft Design, Reston, VA, USA: AIAA, 2010.

[10] Gudmundsson, S., General Aviation Aircraft Design: Applied Methods and Procedures, Oxford, Great Britain: ButterworthHeinemann, 2014.

[11] Mattingly, J. D., Heiser, W. H., and Pratt, D. T., Aircraft Engine Design, 2nd ed., Reston, VA, USA: AIAA, 2002.

[12] Roskam, J., Airplane Design Part I-VIII, Wichita, KS, USA : Roskam Aviation and Engineering Corp., 1985.

[13] Loftin, L. K., Jr., Subsonic Aircraft: Evolution and the Matching of Size to Performance, NASA-RP-1060, Langley, VA, USA: NASA Langley, 1980.

https://ntrs.nasa.gov/search.jsp?R=19800020744.

[14] Herzog, J., Artist, Dornier Do 228NG at ILA Berlin Air Show 2012. [Art]. Wikipedia, 2012.

[15] Juretzko, P. G., Immer, M. and Wildi, J., "Performance analysis of a hybrid-electric retrofit of a RUAG Dornier Do 228NG," CEAS Aeronautical Journal, 26 Sep 2019. https://doi.org/10.1007/s13272-019-00420-2

[16] Hofmann, J., Stumpf, E., Weintraub, D., Köhler, J., Pham, D., Schneider, M., Dickhoff, J., Burkhart, B., Reiner, G., Spiller, M. and Werner, E. A., "A Comprehensive Approach to the Assessment of a Hybrid Electric Powertrain for Commuter Aircraft," in AIAA Aviation Forum 2019, Dallas, TX, USA, 2019. https://doi.org/10.2514/6.2019-3678

[17] RUAG Aerospace Services GmbH, "Dornier 228 Advanced Commuter (AC) Facts \& Figures," Wessling, Germany, 2015.

[18] Dornier GmbH, Logistic, Pilot's Operating Handbook Including the LBA Approved Airplane Flight Manual - Dornier 228100, Munich, Germany: Dornier GmbH, 1983.

[19] Honeywell, "TPE331-10 Turboprop Engine Brochure," Honeywell Aerospace, Phoenix, TX, USA, 2016.

[20] IHS Markit, "RUAG (Dornier) 228 NG," Jane's All the World's Aircraft: Development \& Production, 23 January 2019. [Online]. Available: https://janes.ihs.com/JAWADevelopmentProduction/Display/jawaa704-jawa. [Accessed 7 November 2019].

[21] Finger, D. F., Braun, C., and Bil, C., "Initial Sizing Methodology for Hybrid-Electric General Aviation Aircraft," Journal of Aircraft, 2019. https://doi.org/10.2514/1.C035428

[22] Finger, D. F., Braun, C., and Bil, C., "Case Studies in Initial Sizing for Hybrid-Electric General Aviation Aircraft," in AIAA/IEEE Electric Aircraft Technologies Symposium (EATS), Cincinnati, IN, USA, 2018. https://doi.org/10.2514/6.2018-5005 
[23] Rings, R., Ludowicy, J., Finger, D. F., and Braun, C., "Sizing Studies of Light Aircraft with Parallel Hybrid Propulsion Systems," in 67. Deutscher Luft- und Raumfahrtkongress DLRK 2018, Friedrichshafen, Germany, 2018. https://doi.org/10.25967/480227

[24] Ludowicy, J., Rings, R., Finger, D. F., and Braun, C., "Sizing Studies of Light Aircraft with Serial Hybrid Propulsion Systems," in 67. Deutscher Luft- und Raumfahrtkongress DLRK 2018, Friedrichshafen, Germany, 2018. https://doi.org/10.25967/480226

[25] Finger, D. F., Götten, F., Braun, C., and Bil, C., "Mass, Primary Energy, and Cost - The Impact of Optimization Objectives on the Initial Sizing of Hybrid-Electric General Aviation Aircraft," in 68. Deutscher Luft- und Raumfahrtkongress DLRK 2019, Darmstadt, Germany, 2019. https://doi.org/10.25967/490012

[26] Finger, D. F., Braun, C., and Bil, C., "Comparative Assessment of Parallel-Hybrid-Electric Propulsion Systems for Four Different Aircraft," in 2020 AIAA Aerospace Sciences Meeting, Orlando, FL, USA, 2020.

[27] Finger, D. F., Braun, C., and Bil, C., "Initial Sizing for a Family of Hybrid-Electric VTOL General Aviation Aircraft," in 67. Deutscher Luft- und Raumfahrtkongress DLRK 2018, Friedrichshafen, Germany, 2018. https://doi.org/10.25967/480102

[28] de Vries, R., Brown, M. T. H., and Vos, R., "Preliminary Sizing Method for Hybrid-Electric Distributed-Propulsion Aircraft," Journal of Aircraft, Vol. 56, Issue 6, 2019. https://doi.org/10.2514/1.C035388

[29] Hoogreef, M. F. M., Vos, R., de Vries, R., and Veldhuis, L. L. M., "Conceptual Assessment of Hybrid Electric Aircraft with Distributed Propulsion and Boosted Turbofans," in 2019 AIAA Aerospace Sciences Meeting, San Diego, CA, USA, 2019. https://doi.org/10.2514/6.2019-1807

[30] Hoogreef, M. F. M., de Vries, R., Sinnige, T., and Vos, R., "Synthesis of Aero-Propulsive Interaction Studies applied to Conceptual Hybrid-Electric Aircraft Design," in 2020 AIAA Aerospace Sciences Meeting, Orlando, FL, USA, 2020.

[31] Orefice, F., Della Vecchia, P., Ciliberti, D., and Nicolosi, F., "Aircraft Conceptual Design Including Powertrain System Architecture and Distributed Propulsion," in AIAA Propulsion and Energy 2019 Forum, Indianapolis, IN, USA, 2019. https://doi.org/10.2514/6.2019-4465

[32] de Vries, R., Hoogreef, M. F. M., and, Vos, R., "Preliminary Sizing of a Hybrid-Electric Passenger Aircraft Featuring Overthe-Wing Distributed-Propulsion," in 2019 AIAA Aerospace Sciences Meeting, San Diego, CA, USA, 2019. https://doi.org/10.2514/6.2019-1811

[33] de Vries, R., Hoogreef, M. F. M., and Vos, R., "Aeropropulsive Efficiency Requirements for Turboelectric Transport Aircraft," in 2020 AIAA Aerospace Sciences Meeting, Orlando, FL, USA, 2020.

[34] de Vries, R., Brown, M. T. H., and Vos, R., "A Preliminary Sizing Method for Hybrid-Electric Aircraft Including AeroPropulsive Interaction Effects," in 2018 Aviation Technology, Integration, and Operations Conference, Atlanta, GA, USA, 2018. https://doi.org/10.2514/6.2018-4228

[35] Finger, D. F., Braun, C., and Bil, C., "An Initial Sizing Methodology for Hybrid-Electric Light Aircraft," in 2018 Aviation Technology, Integration, and Operations Conference, Atlanta, GA, USA, 2018. https://doi.org/10.2514/6.2018-4229

[36] Torenbeek, E., Synthesis of Subsonic Airplane Design, Delft, The Netherlands: Delft University Press, 1982.

[37] National Academies of Sciences,Engineering, and Medicine, Commercial Aircraft Propulsion and Energy Systems Research: Reducing Global Carbon Emissions, Washington, D.C., USA: National Academies Press, 2016.

[38] Finger, D. F., Götten, F., Braun, C., and Bil, C., "On Aircraft Design Under the Considerationof Hybrid-Electric Propulsion Systems," in The Proceedings of the 2018 Asia-Pacific International Symposium on Aerospace Technology (APISAT 2018), Singapore, Springer, 2019, pp. 1261-1272.

[39] Stoll, A. M., and Mikic, G. V., "Design Studies of Thin-Haul Commuter Aircraft with Distributed Electric Propulsion," in 16th AIAA Aviation Technology, Integration, and Operations Conference,, Washington, D.C., USA, 2016. https://doi.org/10.2514/6.2016-3765

[40] Finger, D. F., Braun, C., and Bil, C., "A Review of Configuration Design for Distributed Propulsion Transitioning VTOL Aircraft," in Asia-Pacific International Symposium on Aerospace Technology - APISAT2017, Seoul, Korea, 2017.

[41] Ko, A., Schetz, J. A., and Mason, W. H., "Assessment of the Potential Advantages of Distributed-Propulsion for Aircraft," in XVI International Symposium on Air Breathing Engines (ISABE), Cleveland, OH, USA, 2003.

[42] Jackson, P., Jane's All the World's Aircraft: Development \& Production 2017-2018, Coulsdon, Great Britain: IHS Markit, 2017.

[43] International Civil Aviation Organization, Annex 6, Operation of Aircraft, Part I: International Commercial Air Transport - Aeroplanes, Montreal, Canada: International Civil Aviation Organization, 2016. 
[44] Hoerner, S. F., Fluid-Dynamic Drag, Bricktown, NJ, USA: Hoerner Fluid Dynamics, 1965.

[45] Götten, F., Havermann, M., Braun, C., Gómez, F., and Bil, C., "On the Applicability of Empirical Drag Estimation Methods for Unmanned Air Vehicle Design," in 2018 Aviation Technology, Integration, and Operations Conference, Atlanta, GA, USA, 2018.

https://doi.org/10.2514/6.2018-3192

[46] Götten, F., Finger, D. F., Havermann, M., Marino, M., and Bil, C., "A Review of Guidelines and Best Practices for Subsonic Aerodynamic Simulations using RANS CFD," in Asia-Pacific International Symposium on Aerospace Technology - APSIAT 2019, Gold Coast, Australia, 2019.

[47] Hirsch, C., Computational Methods for Inviscid and Viscous Flows, Chichester, Great Britain: Wiley, 2002.

[48] Schlichting, H., and Gersten, K., Boundary-Layer Theory, 9th ed., Berlin, Germany: Springer, 2017.

[49] Obert, E., Aerodynamic Design of Transport Aircraft, Amsterdam, The Netherlands: IOS Press, 2009.

[50] European Aviation Safety Agency, "Acceptable Means of Compliance and Guidance Material to Certification Specifications for Normal-Category Aeroplanes (CS-23)," European Aviation Safety Agency, Cologne, Germany, 2017.

[51] ASTM F3179/F3179M-16, "Standard Specification for Performance of Aeroplanes," ASTM International, West Conshohocken, PA, USA, 2016.

[52] Jansen, R. H., Bowman, C., Jankovsky, A., Dyson, R., and Felder, J., "Overview of NASA Electrified Aircraft Propulsion Research for Large Subsonic Transports," in 53rd AIAA/SAE/ASEE Joint Propulsion Conference, Atlanta, GA, USA, 2017. https://doi.org/10.2514/6.2017-4701 


\section{Appendix}

Table A.1 Additional design parameters and assumptions which are not included in Tables 2, 4, and 7.

\begin{tabular}{|c|c|c|c|}
\hline Parameter & Value & Parameter & Value \\
\hline Number of propellers [-] & 2 & Take-off lift coefficient $C_{L, \mathrm{To}}[-]^{\mathrm{a}}$ & 1.34 \\
\hline PMAD efficiency $\eta_{\mathrm{PM}}[-]$ & 1.0 & $\Delta C_{L \max }$, take-off flaps [-] & 0.73 \\
\hline Gearbox efficiency $\eta_{\mathrm{GB}}[-]$ & 1.0 & $\Delta C_{L \max }$, landing flaps [-] & 0.97 \\
\hline Fuel specific energy $E_{\mathrm{f}}^{*}[\mathrm{MJ} / \mathrm{kg}]^{1, \mathrm{~b}}$ & 42.8 & $\Delta C_{D, \text { min }}$, take-off flaps $[-]^{\mathrm{b}}$ & 0.010 \\
\hline Empty weight fraction OEM/MTOM [- ${ }^{\mathrm{b}}$ & 0.600 & $\Delta C_{D, \text { min }}$, landing flaps $[-]^{\mathrm{b}}$ & 0.045 \\
\hline Empty weight fraction OEM'/MTOM $[-]^{\mathrm{a}}$ & 0.545 & $\Delta C_{D, \min }$, landing gear $[-]^{\mathrm{b}}$ & 0.015 \\
\hline Ambient density $\left[\mathrm{kg} / \mathrm{m}^{3}\right]$ & ISA & $\Delta C_{L, \min D}$, take-off flaps $[-]^{\mathrm{b}}$ & 0 \\
\hline Ambient temperature $\left[{ }^{\circ} \mathrm{C}\right]$ & ISA & $\Delta C_{L, \min D}$, landing flaps $[-]^{\mathrm{b}}$ & 0 \\
\hline Coefficient of rolling friction $[-]^{a}$ & 0.04 & $\Delta e$, take-off flaps $[-]^{\mathrm{b}}$ & 0.040 \\
\hline Maximum lift coefficient (clean) $C_{L \max }[-]$ & 1.70 & $\Delta e$, landing flaps $[-]^{\mathrm{b}}$ & 0.125 \\
\hline
\end{tabular}

a Parameters only required for Method A

${ }^{\mathrm{b}}$ Parameters only required for Method B

${ }^{1}$ Note that $\mathrm{BSFC}=1 /\left(\eta_{\mathrm{GT}} E_{\mathrm{f}}^{*}\right)$

Table A.2 Assumed aircraft properties per performance constraint and mission segment. A dash (-) indicates that the quantity is not an input, but a computed value.

\begin{tabular}{|c|c|c|c|c|c|c|}
\hline & Throttle [-] & Velocity $[\mathrm{m} / \mathrm{s}]$ & $\begin{array}{c}\text { Mass fraction } \\
\boldsymbol{m} / \boldsymbol{m}_{\mathrm{TO}}[-] \\
\end{array}$ & $\begin{array}{c}\text { Propulsive } \\
\text { efficiency [-] }\end{array}$ & $\begin{array}{c}\text { Flap } \\
\text { setting }\end{array}$ & $\begin{array}{c}\text { Landing } \\
\text { gear position }\end{array}$ \\
\hline \multirow{5}{*}{ 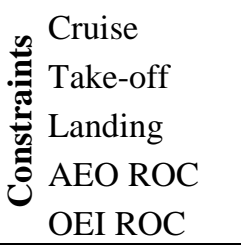 } & 0.9 & 115 & 1 & 0.8 & retracted & retracted \\
\hline & 1 & $-{ }^{\mathrm{a}} / 1.2 V_{\mathrm{s}}^{\mathrm{b}, 1}$ & 1 & 0.7 & take-off & extended \\
\hline & 0.9 & 34.6 & 1 & 0.8 & landing & extended \\
\hline & 0.9 & $V_{\text {best climb }}{ }^{\mathrm{a}} / 1.2 V_{\mathrm{s}}^{\mathrm{b}, 1}$ & 1 & 0.7 & retracted & retracted \\
\hline & 1 & $V_{\text {best climb }}{ }^{\mathrm{a}} / 1.2 V_{\mathrm{s}}^{\mathrm{b}, 1}$ & 1 & 0.65 & retracted & retracted \\
\hline \multirow{7}{*}{ 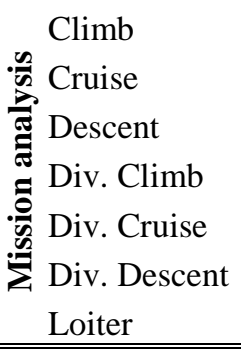 } & 0.9 & - & - & 0.8 & retracted & retracted \\
\hline & - & 115 & - & 0.8 & retracted & retracted \\
\hline & $0,10^{\mathrm{a}} / 0,05^{\mathrm{b}}$ & - & - & 0.8 & retracted & retracted \\
\hline & 0.9 & - & - & 0.8 & retracted & retracted \\
\hline & - & 82 & - & 0.8 & retracted & retracted \\
\hline & $0,10^{\mathrm{a}} / 0,05^{\mathrm{b}}$ & - & - & 0.8 & retracted & retracted \\
\hline & - & $53^{\mathrm{a}} / V_{\max }$ endurance ${ }^{\mathrm{b}}$ & - & 0.8 & retracted & retracted \\
\hline
\end{tabular}

${ }^{a}$ Values used for Method A

b Values used for Method B

${ }^{1}$ Stall speed in the flight condition considered 
Table A.3 Component masses and wing area obtained in the reference aircraft comparison.

\begin{tabular}{cccccccc}
\hline \hline Mission & Method & MTOM $[\mathbf{k g}]$ & OEM $[\mathbf{k g}]$ & $\boldsymbol{m}_{\mathbf{P L}}[\mathbf{k g}]$ & $\boldsymbol{m}_{\mathbf{f}}[\mathbf{k g}]$ & $\boldsymbol{m}_{\mathbf{G T}}[\mathbf{k g}]$ & $\boldsymbol{S}\left[\mathbf{m}^{2}\right]$ \\
\hline $396 \mathrm{~km}$ & Reference & 6400 & 3900 & 1960 & 540 & 349 & 32.0 \\
& A & 6641 & 3866 & 1960 & 615 & 356 & 32.3 \\
& B & 6416 & 3865 & 1960 & 591 & 354 & 32.2 \\
\hline $1280 \mathrm{~km}$ & Reference & 6400 & 3900 & 1325 & 1175 & 349 & 32.0 \\
& A & 6434 & 3862 & 1325 & 1247 & 356 & 32.2 \\
& B & 6403 & 3857 & 1325 & 1221 & 353 & 32.1 \\
\hline $2361 \mathrm{~km}$ & Reference & 6400 & 3900 & 547 & 1953 & 349 & 32.0 \\
& A & 6489 & 3895 & 547 & 2047 & 359 & 32.5 \\
& B & 6188 & 3728 & 547 & 1914 & 341 & 31.0 \\
\hline \hline
\end{tabular}

Table A.4 Component masses and wing area obtained for the four different powertrain configurations in the HEP comparison study. "N/A" indicates no converged design was obtained.

\begin{tabular}{|c|c|c|c|c|c|c|c|c|c|c|c|}
\hline Config. & Mission & Method & $\begin{array}{c}\text { MTOM } \\
{[\mathrm{kg}]} \\
\end{array}$ & $\begin{array}{c}\text { OEM } \\
{[\mathrm{kg}]}\end{array}$ & $\begin{array}{l}m_{\mathrm{PL}} \\
{[\mathrm{kg}]}\end{array}$ & $\begin{array}{c}m_{\mathrm{f}} \\
{[\mathrm{kg}]}\end{array}$ & $\begin{array}{l}m_{\text {bat }} \\
{[\mathrm{kg}]}\end{array}$ & $\begin{array}{l}m_{\mathrm{GT}} \\
{[\mathrm{kg}]}\end{array}$ & $\begin{array}{c}m_{\mathrm{GEN}} \\
{[\mathrm{kg}]}\end{array}$ & $\begin{array}{l}m_{\mathrm{EM}} \\
{[\mathrm{kg}]} \\
\end{array}$ & $\begin{array}{c}S \\
{\left[\mathbf{m}^{2}\right]}\end{array}$ \\
\hline \multirow[t]{6}{*}{ Conv. } & \multirow[t]{2}{*}{$396 \mathrm{~km}$} & $\mathrm{~A}$ & 6216 & 3731 & 1960 & 525 & 0 & 343 & 0 & 0.0 & 31.1 \\
\hline & & B & 6259 & 3770 & 1960 & 529 & 0 & 345 & 0 & 0.0 & 31.4 \\
\hline & \multirow[t]{2}{*}{$1280 \mathrm{~km}$} & A & 6364 & 3820 & 1325 & 1219 & 0 & 352 & 0 & 0.0 & 31.9 \\
\hline & & B & 6446 & 3883 & 1325 & 1238 & 0 & 356 & 0 & 0.0 & 32.3 \\
\hline & \multirow[t]{2}{*}{$2361 \mathrm{~km}$} & A & 7083 & 4252 & 547 & 2285 & 0 & 391 & 0 & 0.0 & 35.5 \\
\hline & & B & 7182 & 4325 & 547 & 2310 & 0 & 396 & 0 & 0.0 & 36.0 \\
\hline \multirow[t]{6}{*}{ Parallel } & \multirow[t]{2}{*}{$396 \mathrm{~km}$} & $\mathrm{~A}$ & 6361 & 3803 & 1960 & 486 & 113 & 316 & 0 & 19.7 & 31.9 \\
\hline & & B & 6385 & 3830 & 1960 & 481 & 115 & 317 & 0 & 18.9 & 32.0 \\
\hline & \multirow[t]{2}{*}{$1280 \mathrm{~km}$} & A & 7058 & 4219 & 1325 & 1222 & 292 & 351 & 0 & 21.8 & 35.4 \\
\hline & & B & 7102 & 4259 & 1325 & 1222 & 296 & 352 & 0 & 21.0 & 35.6 \\
\hline & \multirow[t]{2}{*}{$2361 \mathrm{~km}$} & A & 13472 & 8054 & 547 & 3924 & 947 & 670 & 0 & 41.6 & 67.5 \\
\hline & & B & 13363 & 8014 & 547 & 3863 & 939 & 663 & 0 & 39.5 & 66.9 \\
\hline \multirow[t]{6}{*}{ Serial } & \multirow[t]{2}{*}{$396 \mathrm{~km}$} & A & 8295 & 5490 & 1960 & 697 & 148 & 457 & 256 & 256 & 41.6 \\
\hline & & B & 8246 & 5452 & 1960 & 686 & 148 & 453 & 243 & 244 & 41.3 \\
\hline & \multirow[t]{2}{*}{$1280 \mathrm{~km}$} & A & 12518 & 8284 & 1325 & 2389 & 519 & 690 & 386 & 387 & 62.7 \\
\hline & & B & 12354 & 8168 & 1325 & 2348 & 513 & 679 & 364 & 365 & 61.9 \\
\hline & \multirow[t]{2}{*}{$2361 \mathrm{~km}$} & A & N/A & N/A & N/A & N/A & N/A & N/A & N/A & N/A & N/A \\
\hline & & $\mathrm{B}$ & N/A & N/A & N/A & N/A & N/A & N/A & N/A & N/A & N/A \\
\hline \multirow[t]{6}{*}{ Electric } & \multirow[t]{2}{*}{$396 \mathrm{~km}$} & $\mathrm{~A}$ & 8168 & 4704 & 1960 & 0 & 1504 & 0 & 0 & 252 & 40.9 \\
\hline & & B & 8294 & 4784 & 1960 & 0 & 1550 & 0 & 0 & 245 & 41.6 \\
\hline & \multirow[t]{2}{*}{$1280 \mathrm{~km}$} & A & N/A & N/A & N/A & N/A & N/A & N/A & N/A & N/A & N/A \\
\hline & & B & N/A & N/A & N/A & N/A & N/A & N/A & N/A & N/A & N/A \\
\hline & \multirow[t]{2}{*}{$2361 \mathrm{~km}$} & A & N/A & N/A & N/A & N/A & N/A & N/A & N/A & N/A & N/A \\
\hline & & $\mathrm{B}$ & N/A & N/A & N/A & N/A & N/A & N/A & N/A & N/A & N/A \\
\hline
\end{tabular}


Table A.5 Taxi, take-off, and landing energy fractions assumed for Method B, based on the estimations of Method A, for the three missions considered. Energy fractions expressed as a percentage of total installed energy (including reserves). "N/A" indicates no converged design was obtained.

\begin{tabular}{|c|c|c|c|c|}
\hline & & $\begin{array}{c}\text { Short range } \\
R=396 \mathrm{~km}, \\
m_{\mathrm{PL}}=1960 \mathrm{~kg}\end{array}$ & $\begin{array}{c}\text { Medium range } \\
R=1280 \mathrm{~km}, \\
m_{\mathrm{PL}}=1325 \mathrm{~kg}\end{array}$ & $\begin{array}{l}\text { Long range } \\
R=2361 \mathrm{~km}, \\
m_{\mathrm{PL}}=547 \mathrm{~kg}\end{array}$ \\
\hline \multirow[t]{2}{*}{ Conventional } & Taxi out $\&$ take-off & $2.6 \%$ & $1.3 \%$ & $0.8 \%$ \\
\hline & Landing \& taxi in & $1.6 \%$ & $0.8 \%$ & $0.5 \%$ \\
\hline \multirow[t]{2}{*}{ Parallel } & Taxi out $\&$ take-off & $2.1 \%$ & $0.9 \%$ & $0.6 \%$ \\
\hline & Landing \& taxi in & $0.7 \%$ & $0.3 \%$ & $0.2 \%$ \\
\hline \multirow[t]{2}{*}{ Serial } & Taxi out $\&$ take-off & $2.2 \%$ & $0.9 \%$ & N/A \\
\hline & Landing \& taxi in & $0.7 \%$ & $0.3 \%$ & N/A \\
\hline \multirow[t]{2}{*}{ Electric } & Taxi out \& take-off & $1.6 \%$ & N/A & N/A \\
\hline & Landing \& taxi in & $0.1 \%$ & N/A & N/A \\
\hline
\end{tabular}

Table A.6 Hybridization-ratio sweep results obtained from methods A and $B\left(m_{P L}=1960 \mathrm{~kg}, R=396 \mathrm{~km}\right.$, $\left.E_{\text {bat }}^{*}=1500 \mathrm{Wh} / \mathrm{kg}\right)$.

\begin{tabular}{cccccccccc}
\hline \hline \multicolumn{1}{c}{ Parallel } & \multicolumn{4}{c}{ Serial } \\
$\boldsymbol{H}_{\boldsymbol{p}}$ & \multicolumn{2}{c}{ MTOM $[\mathbf{k g}]$} & \multicolumn{2}{c}{ PREE [-] } & \multicolumn{2}{c}{ MTOM [kg] } & \multicolumn{2}{c}{ PREE [-] } \\
{$[-]$} & A & B & A & B & A & B & A & B \\
\hline 0.0 & 6216 & 6258 & 0.577 & 0.559 & 8321 & 8258 & 0.390 & 0.392 \\
0.1 & 6361 & 6386 & 0.611 & 0.608 & 8295 & 8256 & 0.426 & 0.426 \\
0.2 & 6515 & 6552 & 0.650 & 0.647 & 8271 & 8257 & 0.468 & 0.466 \\
0.3 & 6679 & 6727 & 0.698 & 0.694 & 8250 & 8259 & 0.519 & 0.515 \\
0.4 & 6855 & 6912 & 0.757 & 0.752 & 8231 & 8262 & 0.582 & 0.575 \\
0.5 & 7042 & 7109 & 0.832 & 0.825 & 8214 & 8266 & 0.661 & 0.652 \\
0.6 & 7241 & 7318 & 0.930 & 0.919 & 8200 & 8272 & 0.766 & 0.752 \\
0.7 & 7452 & 7540 & 1.064 & 1.045 & 8188 & 8277 & 0.909 & 0.889 \\
0.8 & 7676 & 7774 & 1.255 & 1.225 & 8179 & 8281 & 1.118 & 1.087 \\
0.9 & 7914 & 8019 & 1.549 & 1.500 & 8172 & 8281 & 1.449 & 1.402 \\
1.0 & 8168 & 8269 & 2.060 & 1.976 & 8168 & 8269 & 2.060 & 1.976 \\
\hline \hline
\end{tabular}


Table A.7 Range sweep results obtained from methods $A$ and $B\left(m_{\mathrm{PL}}=1960 \mathrm{~kg}, E_{\mathrm{bat}}^{*}=1500 \mathrm{Wh} / \mathrm{kg}\right.$, $\left.H_{p}=0.1\right)$. "N/A" indicates no converged design was obtained.

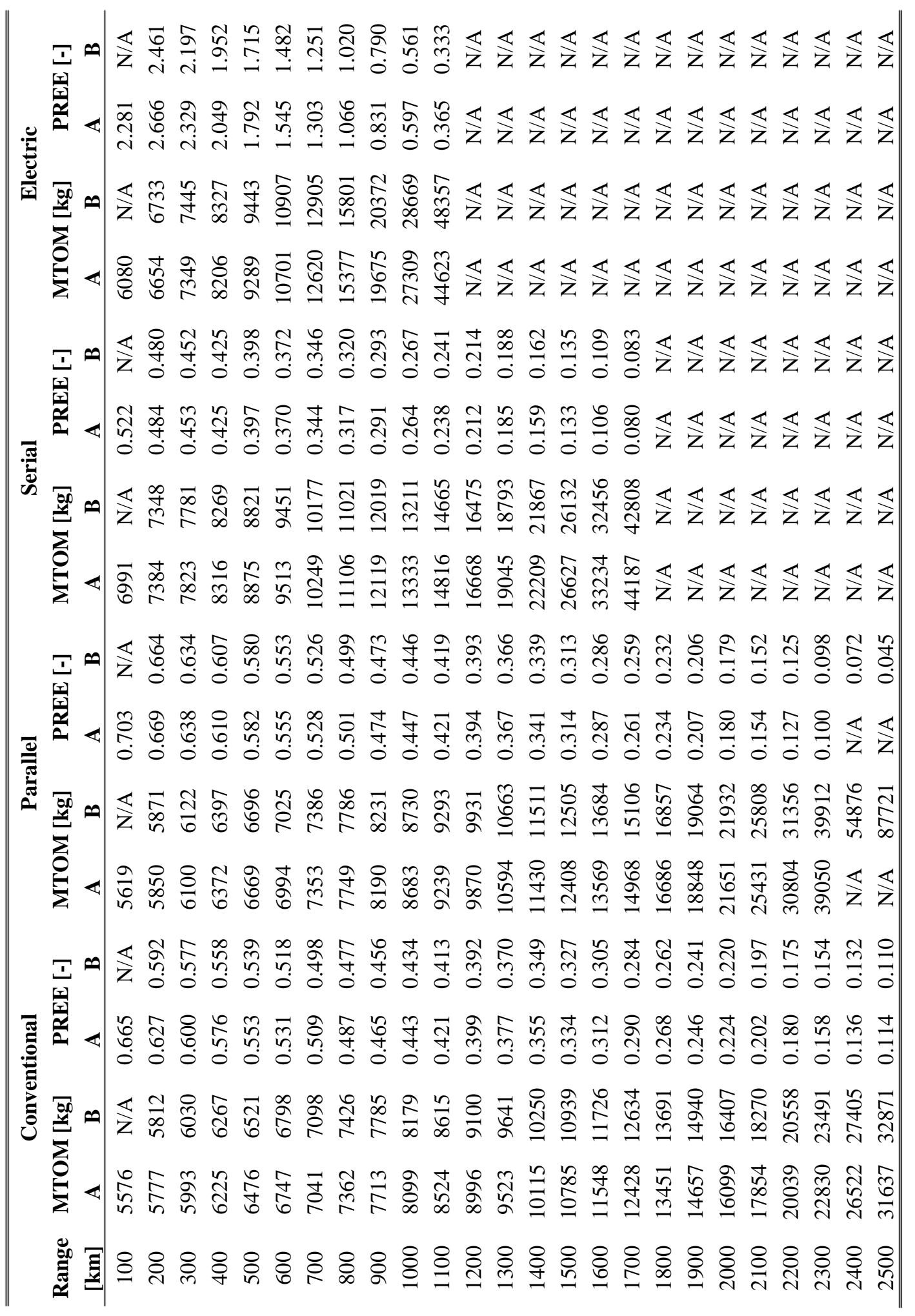


Table A.8 Battery specific-energy sweep results obtained from methods $A$ and $B\left(m_{\mathrm{PL}}=1960 \mathrm{~kg}, R=396\right.$ $\left.\mathrm{km}, H_{p}=0.1\right)$. "N/A" indicates no converged design was obtained.

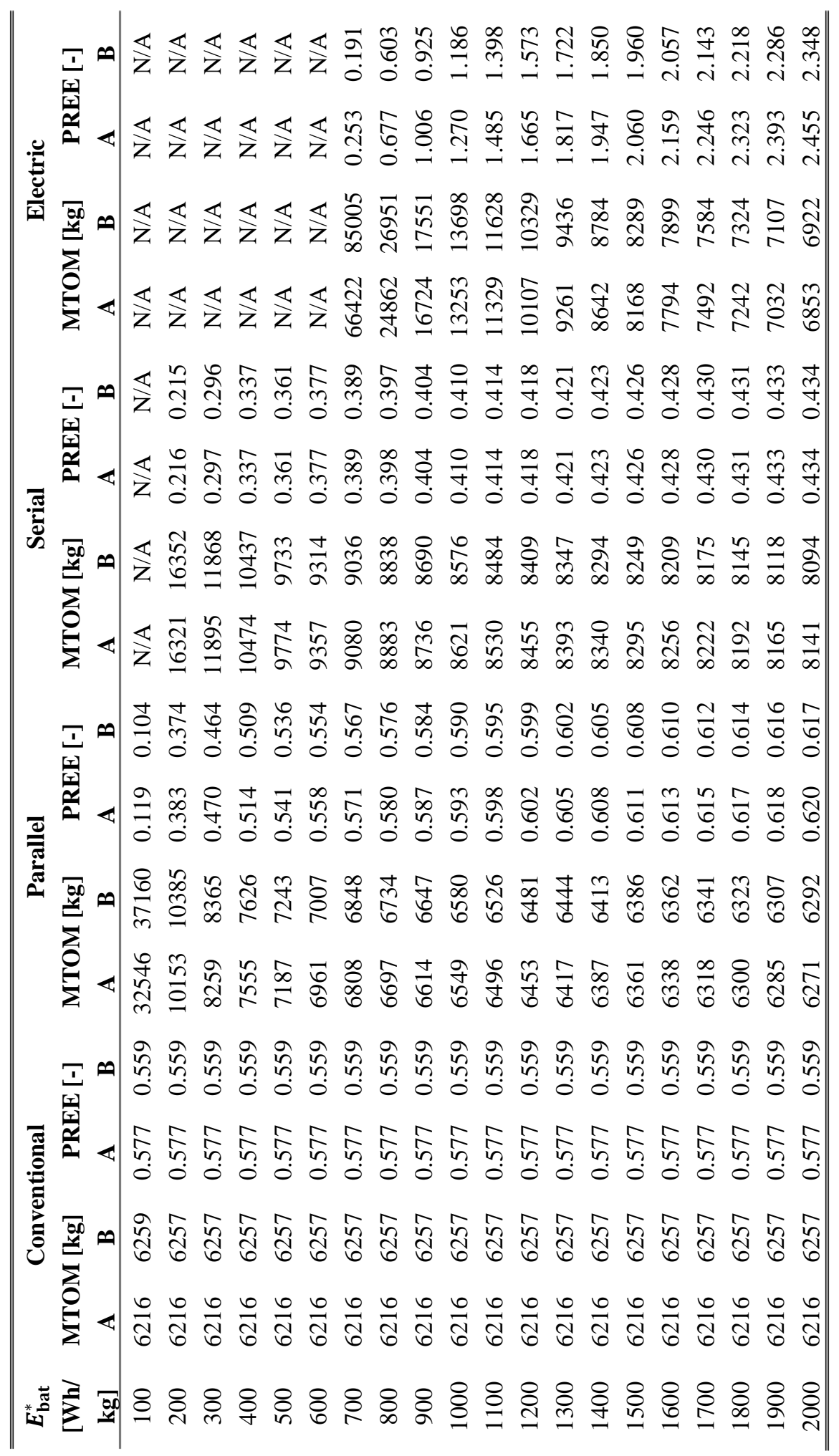

